\title{
Synoptic relationships between surface Chlorophyll- $a$ and diagnostic pigments specific to phytoplankton functional types
}

\author{
T. Hirata ${ }^{1,2, *, * *}$, N. J. Hardman-Mountford ${ }^{1,2}$, R. J. W. Brewin ${ }^{1,3}$, J. Aiken ${ }^{1}$, R. Barlow ${ }^{4,5}$, K. Suzuki ${ }^{6}$, T. Isada ${ }^{7}$, \\ E. Howell ${ }^{8}$, T. Hashioka ${ }^{9,10}$, M. Noguchi-Aita ${ }^{7,10}$, and Y. Yamanaka ${ }^{6,9,10}$ \\ ${ }^{1}$ Plymouth Marine Laboratory (PML), UK \\ ${ }^{2}$ National Centre for Earth Observation (NCEO), UK \\ ${ }^{3}$ School of Marine Science and Engineering, University of Plymouth, UK \\ ${ }^{4}$ Bayworld Centre for Research \& Education, South Africa \\ ${ }^{5}$ Marine Research Institute, University of Cape Town, South Africa \\ ${ }^{6}$ Faculty of Environmental Earth Science, Hokkaido University, Japan \\ ${ }^{7}$ Faculty of Fisheries Sciences, Hokkaido University, Japan \\ ${ }^{8}$ Pacific Island Fisheries Science Centre, National Oceanic and Atmospheric Administration (NOAA), USA \\ ${ }^{9}$ Core Research for Evolution Science and Technology (CREST), Japan Science Technology Agency, Japan \\ ${ }^{10}$ Research Institute for Global Change, Japan Agency for Marine-Earth Science and Technology (JAMSTEC), Japan \\ *now at: Faculty of Environmental Earth Science, Hokkaido University, Japan \\ ** now at: Core Research for Evolution Science and Technology (CREST), Japan Science Technology Agency, Japan
}

Received: 29 July 2010 - Published in Biogeosciences Discuss.: 1 September 2010

Revised: 6 January 2011 - Accepted: 25 January 2011 - Published: 11 February 2011

\begin{abstract}
Error-quantified, synoptic-scale relationships between chlorophyll- $a(\mathrm{Chl}-a)$ and phytoplankton pigment groups at the sea surface are presented. A total of ten pigment groups were considered to represent three Phytoplankton Size Classes (PSCs, micro-, nano- and picoplankton) and seven Phytoplankton Functional Types (PFTs, i.e. diatoms, dinoflagellates, green algae, prymnesiophytes (haptophytes), pico-eukaryotes, prokaryotes and Prochlorococcus sp.). The observed relationships between Chl- $a$ and PSCs/PFTs were well-defined at the global scale to show that a community shift of phytoplankton at the basin and global scales is reflected by a change in Chl- $a$ of the total community. Thus, Chl- $a$ of the total community can be used as an index of not only phytoplankton biomass but also of their community structure. Within these relationships, we also found nonmonotonic variations with Chl- $a$ for certain pico-sized phytoplankton (pico-eukaryotes, Prokaryotes and Prochlorococcus sp.) and nano-sized phytoplankton (Green algae, prymnesiophytes). The relationships were quantified with a leastsquare fitting approach in order to enable an estimation of the PFTs from Chl- $a$ where PFTs are expressed as a percentage
\end{abstract}

of the total Chl- $a$. The estimated uncertainty of the relationships depends on both PFT and Chl- $a$ concentration. Maximum uncertainty of $31.8 \%$ was found for diatoms at Chl$a=0.49 \mathrm{mg} \mathrm{m}^{-3}$. However, the mean uncertainty of the relationships over all PFTs was $5.9 \%$ over the entire Chl- $a$ range observed in situ $\left(0.02<\mathrm{Chl}-a<4.26 \mathrm{mg} \mathrm{m}^{-3}\right)$. The relationships were applied to SeaWiFS satellite Chl- $a$ data from 1998 to 2009 to show the global climatological fields of the surface distribution of PFTs. Results show that microplankton are present in the mid and high latitudes, constituting only $\sim 10.9 \%$ of the entire phytoplankton community in the mean field for 1998-2009, in which diatoms explain $\sim 7.5 \%$. Nanoplankton are ubiquitous throughout the global surface oceans, except the subtropical gyres, constituting $\sim 45.5 \%$, of which prymnesiophytes (haptophytes) are the major group explaining $\sim 31.7 \%$ while green algae contribute $\sim 13.9 \%$. Picoplankton are dominant in the subtropical gyres, but constitute $\sim 43.6 \%$ globally, of which prokaryotes are the major group explaining $\sim 26.5 \%$ (Prochlorococcus $\mathrm{sp}$. explaining $22.8 \%$ ), while pico-eukaryotes explain $\sim 17.2 \%$ and are relatively abundant in the South Pacific. These results may be of use to evaluate global marine ecosystem models.

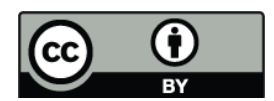

Correspondence to: T. Hirata

(tahi@ees.hokudai.ac.jp)

Published by Copernicus Publications on behalf of the European Geosciences Union. 


\section{Introduction}

Phytoplankton play numerous roles in ocean biogeochemical cycling: $\mathrm{CO}_{2}$ is utilised to form organic matter via photosynthetic processes and is then released through respiration; macro- and micronutrients are assimilated by phytoplankton for their metabolic needs. While these processes are common to all phytoplankton, some species have specific chemical requirements for their distinct physiological processes, thereby fulfilling a range of different functional roles in ocean biogeochemical cycles: $\mathrm{Si}$ is utilised by diatoms, $\mathrm{Ca}$ by coccolithophores and $\mathrm{N}_{2}$ by some cyanobacteria (e.g. Trichodesmium). Some phytoplankton such as dinoflagellates and prymnesiophytes (haptophytes) appear responsible for enhanced dimethylsulfoniopropionate (DMSp) production in the ocean, contributing to an exchange of $S$ between the ocean and atmosphere (Sunda et al., 2002). These functional differences have led to phytoplankton being classified according to their biogeochemical functions.

In order to quantify the contributions of these phytoplankton functional types (PFTs) to biogeochemical cycling on a global scale, it is first important to understand their spatiotemporal variability throughout the oceans. Ocean biogeochemistry and ecosystem models, such as NEMURO (Aita et al., 2007; Hashioka and Yamanaka, 2007; Kishi et al., 2007), ERSEM (Blackford et al., 2004; Petihakis et al., 2005), PlankTOM-5 and -10 (Le Quéré et al., 2005; Le Quéré and Pesant, 2009) and NOBM (e.g. Gregg et al., 2003; Gregg and Casey, 2007), can be used to investigate the processes responsible for spatial and temporal variability of phytoplankton populations at large scales and provide some potential for forecasting future ocean states. The populations within these models are generally based on biogeochemical function (usually linked to size), rather than explicit taxonomy. Validation of these models is essential, which is cumbersome when large spatial and temporal scales are concerned (Allen et al., 2010), so a globally consistent approach based on a functional classification of marine phytoplankton groups is required.

In general, the agreement between functional- and taxonomic- or size-based classifications, while far from universal, is adequate for comparisons to be undertaken with current model estimates. The close similarity between the functional classification of Le Quéré et al. (2005) and size structure or taxonomic groupings (Sieburth et al., 1978; microplankton $>20 \mu \mathrm{m}$, nanoplankton $20-2 \mu \mathrm{m}$, picoplankton $<2 \mu \mathrm{m})$ is shown in Table 1. On the other hand, direct estimation of phytoplankton community structure at basin to global scales is non-trivial. Traditional microscopic observations, flow cytometry, pigment and DNA analyses have all been used to classify phytoplankton community structure in situ. Pigment analysis by High Performance Liquid Chromatography (HPLC) has become increasingly popular in oceanography because of the relatively large number of samples that can be collected and analysed rapidly, categorizing the phytoplankton community (at least according to broad classes based on size or taxonomy) much faster than with traditional microscopy. Even so, spatial and temporal coverage is inevitably limited by the mismatch in scales between in situ observational capabilities and the vast size of the oceans.

Since the launch of space-borne ocean colour sensors, satellites have been able to provide a continuous record of multi-spectral optical observations of the ocean surface, that at certain wavelengths are strongly affected by concentrations of the ubiquitous photosynthetic pigment, chlorophyll$a(\mathrm{Chl}-a)$. As a result, ocean colour measurements have been used to observe Chl- $a$ at the global scale (O'Reilly et al., 1998). From this proxy of phytoplankton biomass, variations in oceanic phytoplankton populations and global marine primary production have been investigated (e.g. Longhurst et al., 1995; Behrenfeld and Falkowski, 1997; Behrenfeld et al., 2006; Polovina et al., 2008). More recently, this technology has revealed the capability for more in depth investigation of phytoplankton community structure by means of Phytoplankton Functional Types, PFTs, or size classes, PSCs (e.g. Ciotti and Bricaud, 2006; Sathyendranath et al., 2004; Alvain et al., 2005, 2008; Devered et al., 2006; Uitz et al., 2006; Aiken et al., 2007, 2009; Hirata et al., 2008; Raitsos et al., 2008; Bracher et al., 2009; Brewin et al., 2010, 2011; Mouw and Yorder, 2010; Kostadinov et al., 2010), allowing the extrapolation of in situ PFT/PSC descriptions to larger spatial scales with better temporal resolution, thus providing a method to more adequately evaluate biogeochemical and ecosystem models.

The current suite of satellite PFT algorithms are derived from either (1) the "dominance" of specific PFTs or size classes without estimation of their fractional contributions to the overall phytoplankton community (Sathyendranath et al., 2004; Alvain et al., 2005, 2008; Hirata et al., 2008; Raitsos et al., 2008), or (2) a limited number of phytoplankton groups (Devred et al., 2006; Uitz et al., 2006; Bracher et al., 2009; Brewin et al., 2010; Kostadinov et al., 2010), for which the fractional contribution is in some cases estimated. This paper bridges the gap between these approaches by estimating the fractional contribution of an increased number of PFTs (7 PFTs), partitioned within 3 size classes where appropriate. The novelty of this work is that, in addition to size classes such as micro-, nano- and picoplankton, we estimate diatoms, dinoflagellates, prymnesiophytes (haptophytes), green algae, pico-eukaryotes, prokaryotes and Prochlorococcus sp. These PFTs have not been globally estimated simultaneously from satellite by previous studies. The relationships between phytoplankton Chl- $a$ concentrations and the phytoplankton functional types determined from their biomarker pigments were quantified from a global in situ data set, and the uncertainty of these relationships was assessed to enable satellite observations of PFT fields throughout the World's oceans. 
Table 1. Phytoplankton Size Classes (PSCs) and Phytoplankton Functional Types (PFTs) represented by their pigments.

\begin{tabular}{|c|c|c|}
\hline PSCs/PFTs & Diagnostic Pigments & Estimation Formula \\
\hline Microplankton $(>20 \mu \mathrm{m}) * 2$ & Fucoxanthin (Fuco), Peridinin (Perid) & $1.41($ Fuco + Perid $) / \Sigma D P * 2$ \\
\hline Diatoms & Fuco & $1.41 \mathrm{Fuco} / \Sigma \mathrm{DP}^{* 2}$ \\
\hline Dinoflagellates & Perid & $1.41 \mathrm{Perid} / \Sigma \mathrm{DP}^{* 2}$ \\
\hline \multirow[t]{4}{*}{ Nanoplankton $(2-20 \mu \mathrm{m})^{* 1}$} & 19'-Hexanoyloxyfucoxanthin (Hex) & $\begin{array}{l}\left(\mathrm{X}_{n *} 1.27 \mathrm{Hex}+1.01 \mathrm{Chl}-b\right. \\
+0.35 \mathrm{But}+0.60 \mathrm{Allo}) / \Sigma \mathrm{DP}^{* 3}\end{array}$ \\
\hline & Chlorophyll- $b$ (Chl- $b)$ & \\
\hline & Butanoyloxyfucoxanthin (But) & \\
\hline & Alloxanthin (Allo) & \\
\hline Green algae & Chl- $b$ & $1.01 \mathrm{Chl}-b / \Sigma \mathrm{DP}^{* 2}$ \\
\hline $\begin{array}{l}\text { Prymnesiophytes } * 4 \\
\text { (Haptophytes) }\end{array}$ & Hex, But & \\
\hline Picoplankton $(0.2-2 \mu \mathrm{m})^{* 1}$ & Zeaxanthin (Zea), Hex, Chl- $b$ & $\left(0.86 \mathrm{Zea}+\mathrm{Y}_{p} 1.27 \mathrm{Hex}\right) / \Sigma \mathrm{DP}^{* 3}$ \\
\hline Prokaryotes & Zea & $0.86 \mathrm{Zea} / \Sigma \mathrm{DP}^{* 2}$ \\
\hline Pico-eukaryotes $* 5$ & Hex, Chl- $b$ & \\
\hline Prochlorococcus sp. & Divinyl Chlorophyll- $a$ (DVChl- $a$ ) & 0.74 DVChl- $a$ /Chl- $a$ \\
\hline
\end{tabular}

*1 Sieburth et al. (1978)

${ }^{* 2} \Sigma \mathrm{DP}=1.41$ Fuco +1.41 Perid $+1.27 \mathrm{Hex}+0.6$ Allo +0.35 But $+1.01 \mathrm{Chl}-b+0.86 \mathrm{Zea}=$ Chl $-a($ Uitz et al., 2006)

${ }^{*} \mathrm{X}_{n}$ indicates a proportion of nanoplankton contribution in Hex. Similarly $\mathrm{Y}_{p}$ indicates a proportion of picoplankton in Hex, (Brewin et al., 2010)

${ }^{* 4}$ Given that contributions of Allo to nanoplankton were only a few percent in our data set, haptophytes were approximated to Nano minus Green Algae (see also Fig. 2 caption)

*5 Pico-eukaryotes can be determined from picoplankton minus prokaryotes (see also Fig. 2 caption).

\section{Data and methods}

Phytoplankton pigments derived from High Performance Liquid Chromatography (HPLC) were obtained from various sources, including data collected between 1997-2004 by the Atlantic Meridional Transect programme (AMT) operated by the Plymouth Marine Laboratory (PML, UK) and Natural Environmental Research Council (NERC, UK), the BEAGLE cruise in 2003-2004 by Japan Agency for Marine-Earth Science and TEChnology (JAMSTEC, Japan), data from 1995-2008 in the SeaWiFS Bio-optical archive and Storage System (SeaBASS) operated by the National Aeronautics and Space Administration (NASA, USA), data from 19952003 in the NASA bio-Optical Marine Algorithm Dataset (NOMAD), the SEEDS II iron enrichment experiment in 2004 by the University of Tokyo (Japan), A-line stations in 2005 by Fisheries Research Agency (FRA, Japan), and the Oshoro-Maru cruise by Hokkaido University (HU, Japan) in 2004-2006 (Fig. 1). The data were quality controlled in the following way: Individual pigment data were visually checked and data of clear low-quality (e.g. continuously repeated value over several stations within a cruise, typically low values, suspected as outside the detection limits of an instrument) were removed. Further outliers were determined from the regression of accessory pigments against Chl- $a$ concentration, excluding values beyond the $95 \%$ confidence interval of the regression (Aiken et al., 2009). The data were then sorted by numerical value of Chl- $a$ and smoothed with a 5-point running mean low-pass filter to improve the signal to noise ratio (Hirata et al., 2008; Brewin et al., 2010).
This resulted in a database of 3966 observations. From the quality controlled data, $70 \%$ were used for algorithm development and 30\% were reserved for validation. The validation dataset were constructed in such a way that $30 \%$ of each subdataset (i.e. each cruise or dataset described previously) was sub-sampled using a random number generator, to ensure that each sub-dataset evenly contributed to the validation dataset.

SeaWiFS 9 km Level-3 monthly composites of Chl- $a$ data (O'Reilley et al., 1998) for the period 1998-2009 were obtained from NASA Goddard Space Flight Centre using the 2009 reprocessing which has resulted in improved atmospheric and radiometric corrections, more comprehensive vicarious calibration and corrections to instrument calibration drift over the time series. Validation results show substantially improved agreement with in situ measurements in turbid and highly productive waters (see http://oceancolor.gsfc. nasa.gov/REPROCESSING/R2009/ and linked forum topics for further details). In order to focus on oceanic waters, coastal and shelf waters $(<200 \mathrm{~m})$ were masked out in the SeaWiFS Chl- $a$ data, using the ETOPO5 bathymetry (National Geophysical Data Center, 1988).

Diagnostic Pigment Analysis (DPA) is applied to classify phytoplankton types from HPLC pigment data (Vidussi et al., 2001). DPA defines a suite of Diagnostic Pigments (DP) for specific PFTs that can be quantified relative to the sum of all DP concentrations (i.e. DP/ $\Sigma D P$ ) to estimate the relative abundance of a specific PFT (Table 1). The DPA procedure, originally proposed by Vidussi et al. (2001), was subsequently refined by Uitz et al. (2006) to scale 
Table 2. Equations to estimate fractions [0.0-1.0] of PSCs (Micro-, Nano- and Picoplankton) and PFTs (other). Set PFT fraction to 1.0 if $>1.0$, and 0 if $<0$. To get $\%$ Chl- $a$, multiply 100 to the fractions derived.

\begin{tabular}{|c|c|c|c|c|c|c|c|c|}
\hline PSCs/PFTs & Formula & $\mathrm{a}_{0}$ & $\mathrm{a}_{1}$ & $\mathrm{a}_{2}$ & $a_{3}$ & $\mathrm{a}_{4}$ & $a_{5}$ & $\mathrm{a}_{6}$ \\
\hline Microplankton & {$\left[\mathrm{a}_{0}+\exp \left(\mathrm{a}_{1} \mathrm{x}+\mathrm{a}_{2}\right)\right]^{-1}$} & 0.9117 & -2.7330 & 0.4003 & & & & \\
\hline Diatoms & {$\left[a_{0}+\exp \left(a_{1} x+a_{2}\right)\right]^{-1}$} & 1.3272 & -3.9828 & 0.1953 & - & - & - & - \\
\hline Dinoflagellates & (= Micro-Diatoms) & - & - & - & - & - & - & - \\
\hline Nanoplankton & (= 1-Micro-Pico) & - & - & - & - & - & - & - \\
\hline Green Algae & $\left(a_{0} / y\right) \exp \left[a_{1}\left(x+a_{2}\right)^{2}\right]$ & 0.2490 & -1.2621 & -0.5523 & - & - & - & - \\
\hline $\begin{array}{l}\text { Prymnesiophytes } \\
\text { (Haptophytes) }\end{array}$ & $(\simeq$ Nano-Green Algae $)$ & - & - & - & - & - & - & - \\
\hline $\begin{array}{l}\text { Picoplankton } \\
\text { Prokaryotes }\end{array}$ & $\begin{array}{c}-\left[a_{0}+\exp \left(a_{1} x+a_{2}\right)\right]^{-1}+a_{3} x+a_{4} \\
\left(a_{0} / a_{1} / y\right) \exp \left[a_{2}\left(x+a_{3}\right)^{2} / a_{1}^{2}\right]\end{array}$ & 0.1529 & 1.0306 & -1.5576 & -1.8597 & 2.9954 & - & - \\
\hline \multirow{3}{*}{$\begin{array}{l}\text { Pico-eukaryotes } \\
\text { Prochlorococcus sp. }\end{array}$} & $+a_{4} x^{2}+a_{5} x+a_{6}$ & 0.0067 & 0.6154 & -19.5190 & 0.9643 & 0.1027 & -0.1189 & 0.0626 \\
\hline & (= Pico-Prokaryotes) & - & - & - & - & - & - & - \\
\hline & $\begin{array}{c}\left(a_{0} / a_{1} / y\right) \exp \left[a_{3}\left(x+a_{4}\right)^{2} / a_{1}^{2}\right] \\
+a_{4} x^{2}+a_{5} x+a_{6}\end{array}$ & 0.0099 & 0.6808 & -8.6276 & 0.9668 & 0.0074 & -0.1621 & 0.0436 \\
\hline
\end{tabular}

$\mathrm{x}=\log _{10}(\mathrm{Chl}-a) ; \mathrm{y}=\mathrm{Chl}-a$

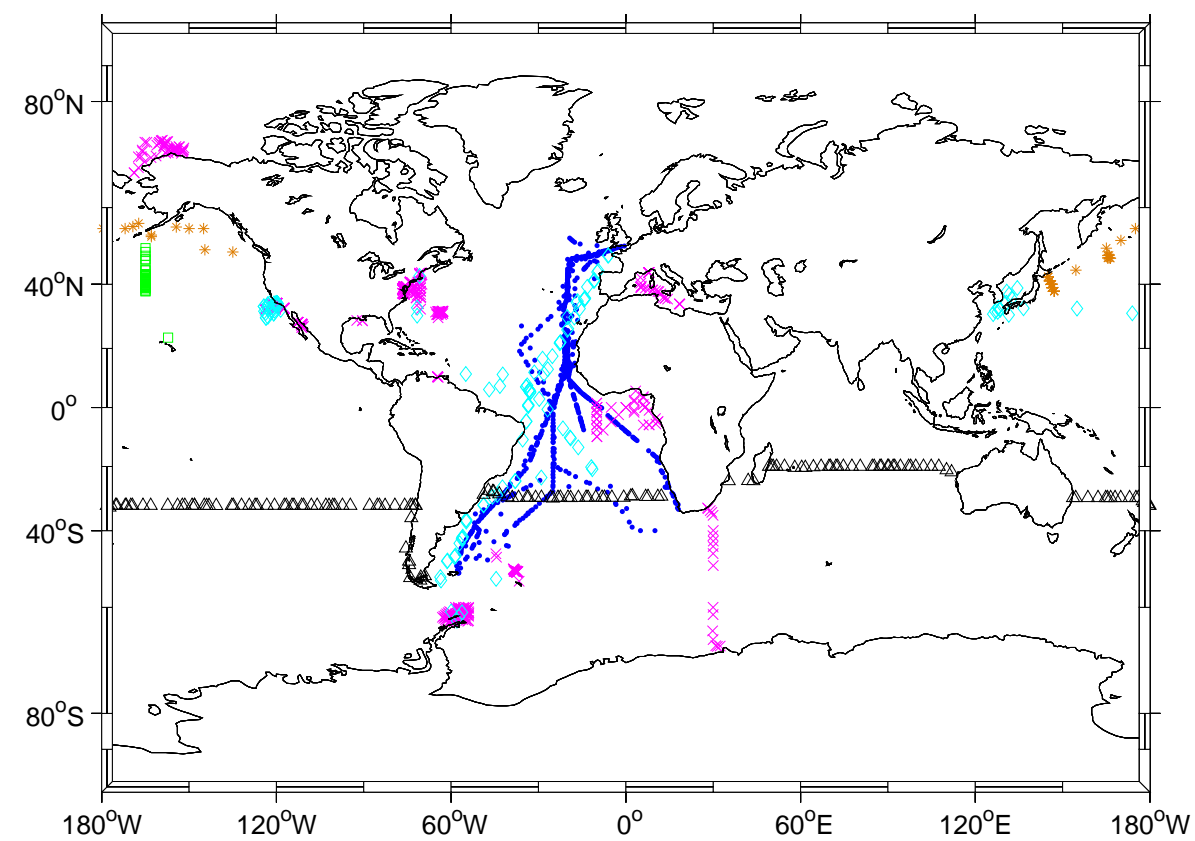

Fig. 1. Distribution of phytoplankton pigment data used in this study; blue dot: the NERC AMT cruise (Aiken et al., 2009), black triangle: the JAMSTEC BEAGLE cruise (Barlow et al., 2007), cyan diamond: the NASA NOMAD (Werdell and Bailey, 2005), magenta cross: the NASA SeaBASS, brown star: the SEEDS II cruise (Suzuki et al., 2005) + A-line stations (Isada et al., 2009), green square: the HU Oshoro-maru cruise.

$\Sigma$ DP to Chl- $a$, permitting the application of DPA-based approaches to satellite-derived Chl- $a$. In addition, Hirata et al. (2008) used the refined DPA to separate pico-eukaryotes from nano-eukaryotes, and Brewin et al. (2010) developed a method to quantify the relationship, which is used in the present work. Here, DPA is further refined to account for ambiguity of the fucoxanthin (Fuco) signal. Fuco is defined as a DP for Diatoms by Vidussi et al. (2001). However, Fuco is also a precursor pigment of 19'-Hexanoyloxyfucoxanthin (Hex), the DP for prymnesiophytes (haptophytes), and can co-occur in this group. Fuco is also contained in the other heterokonts (e.g. chrysophytes, bolidophytes) and dinoflagellates, which are relatively abundant in coastal environments (Wright and Jeffrey, 2006). Thus, diatoms 

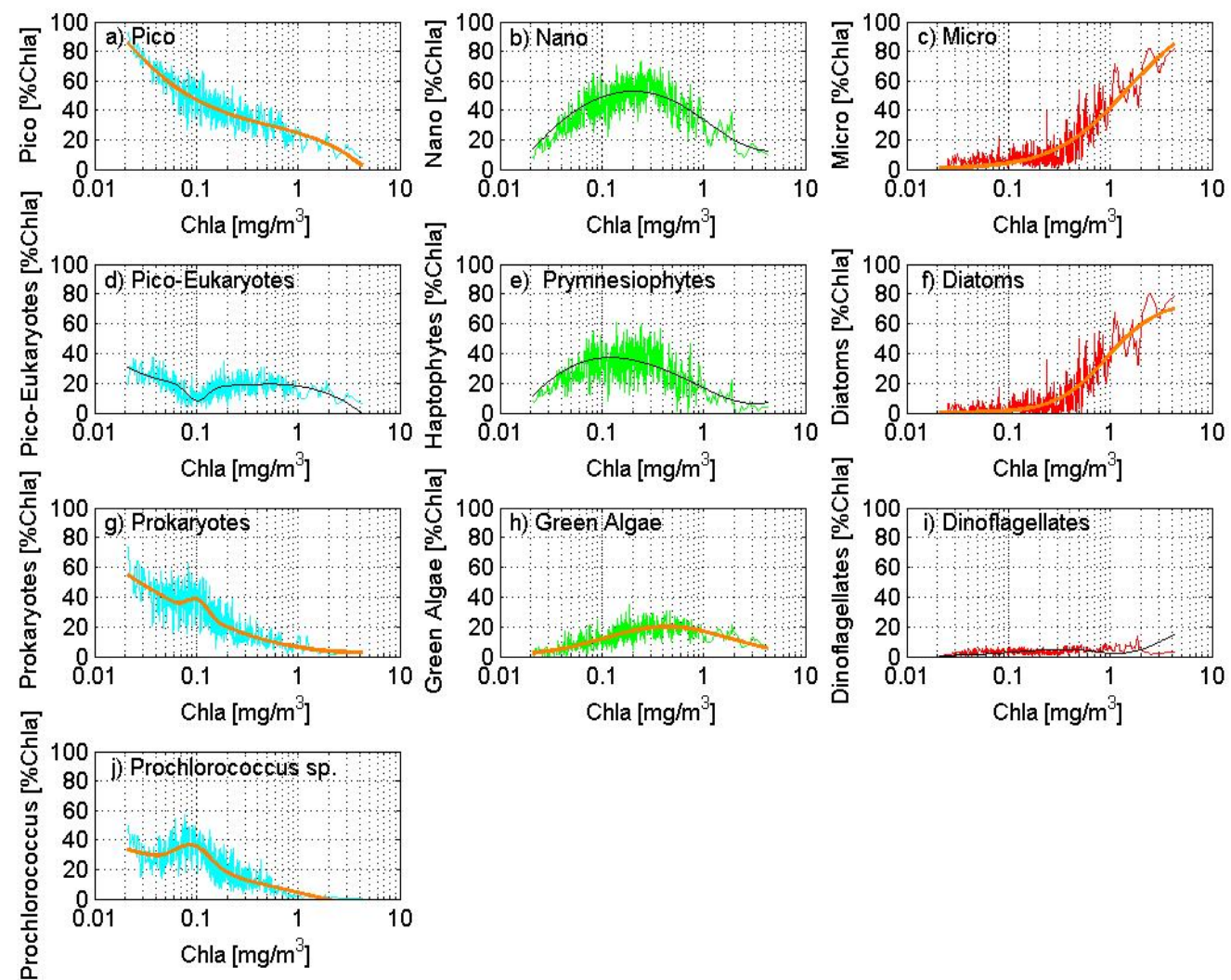

Fig. 2. Global relationships between Chl- $a$ and \% Chl- $a$ of each PFT; (a) Picoplankton, (b) Nanoplankton, (c) Microplankton, (d) Pico-eukaryotes, (e) Prymnesiophytes (Haptophyotes), (f) Diatoms, (g) Prokaryotes, (h) Green algae, (i) Dinoflagellates, (j) Prochlorococcus sp. The orange thick curves are the least-square fits to the original data (a, c, f, g, h, j), whereas the black thin curves are the fits indirectly derived from the least square fits $\left(\mathbf{b}, \mathbf{d}, \mathbf{i}\right.$; e.g. $100 \times \mathrm{Nano}_{\mathrm{fit}}$ $[\%]=100 \times\left(1.0-\right.$ Micro $_{\text {fit }}-$ Pico $\left._{\text {fit }}\right)$; see also Table 2. Refer to Table 3 for goodness of the fits. The following mass-balances are maintained; Microplankton + Nanoplankton + Picoplankton $)=1.0 ;$ Diatoms + Dinoflagellates = Microplankton; Prymnesiophytes $($ Haptophytes $)+$ GreenAlgae $\simeq$ Nanoplankton; Prokaryotes + PicoEukaryotes $=$ Picoplankton.

could be overestimated in DPA. Hirata et al. (2008) found a non-negligible proportion of Fuco within the oligotrophic gyres of the subtropical Atlantic, where small prokaryotes (predominantly Prochlorococcus sp. and Synechococcus sp.) and pico-eukaryotes (which can partly belong to the prymnesiophytes (haptophytes) so may also contain Hex) usually dominate the phytoplankton community (Zubkov et al., 1998; Tarran et al., 2006). In these oligotrophic waters, Chl- $a$ is low $\left(<0.25 \mathrm{mg} \mathrm{m}^{-3}\right.$, Aiken et al., 2009), therefore, it is more reasonable to assume that the background level of Fuco detected results from smaller prymnesiophytes (haptophytes) rather than diatoms which are more prevalent in eutrophic waters. Therefore, we calculated a baseline for the Fuco/Hex ratio, (Fuco/Hex) baseline, using Fuco and Hex in the Chl- $a$ range less than $0.25 \mathrm{mg} \mathrm{m}^{-3}$ in the original data set (denoted as Fuco $_{\text {original }}$ and $\mathrm{Hex}_{\text {original }}$, respectively). The proportion of Fuco as a diatom biomarker is then corrected so that $\mathrm{Fuco}_{\text {corrected }}=\mathrm{Fuco}_{\text {original }}-(\mathrm{Fuco} / \mathrm{Hex})_{\text {baseline }} \times \mathrm{Hex}_{\text {original }}$.
The Fuco conversion is only significant in the lower Chl- $a$ range $\left(<0.5 \mathrm{mg} \mathrm{m}^{-3}\right)$ and is negligible for higher Chl- $a$ values.

Using these HPLC pigment signals, PSCs and PFTs are defined and classified as in Table 1, and their relationships to Chl- $a$ are analysed below.

\section{Results}

\subsection{Synoptic relationships between $\mathrm{Chl}-a$ and phytoplankton functional types (PFTs)}

Figure 2 shows the global relationships between Chl- $a$ and the fraction of DP associated with each PFT, derived from in situ HPLC. A clear co-variability is found between Chl- $a$ and DP for each PFT. While Chl- $a$ is commonly used as an index of phytoplankton biomass, the co-variability indicates that Chl- $a$ is also an index of phytoplankton community structure. For microplankton, the fractional contribution to Chl- $a$ 
Table 3. Statistical results of the reconstructed relationships between Chl- $a$ and PSCs/PFTs against in situ data.

\begin{tabular}{lcccccc}
\hline $\begin{array}{l}\text { PSCs/ } \\
\text { PFT }\end{array}$ & $\begin{array}{r}\text { Observed } \\
\text { range of \% Chl- } a\end{array}$ & $r^{2}$ & $p$ & RMSE [\%] & $\begin{array}{c}\text { Max. Abs. } \\
\text { Error [\%] }\end{array}$ & $\begin{array}{c}\text { Chl- } a \text { at Max. } \\
\text { Abs. Error [mg m }{ }^{3} \text { ] }\end{array}$ \\
\hline Microplankton & $0-82$ & 0.76 & $<0.001$ & 6.7 & 31.1 & 0.49 \\
Diatoms & $0-80$ & 0.77 & $<0.001$ & 6.3 & 31.8 & 0.49 \\
Dinoflagellates & $0-14$ & 0.00 & $<0.190$ & 2.1 & 12.0 & 4.26 \\
Nanoplankton & $7-73$ & 0.65 & $<0.001$ & 7.6 & 27.6 & 0.12 \\
Green algae & $0-37$ & 0.59 & $<0.001$ & 4.2 & 17.8 & 0.19 \\
Prymnesiophytes & $0-61$ & 0.41 & $<0.001$ & 8.4 & 29.5 & 0.12 \\
(Haptophytes) & & & & & & 0.08 \\
Picoplankton & $7-93$ & 0.82 & $<0.001$ & 6.1 & 23.8 & 0.08 \\
Prokaryotes & $1-73$ & 0.75 & $<0.001$ & 7.1 & 25.2 & 0.19 \\
PicoEukaryotes & $3-37$ & 0.46 & $<0.001$ & 4.6 & 16.6 & 0.06 \\
Prochlorococcus sp. & $0-58$ & 0.75 & $<0.001$ & 6.1 & 21.4 & 0.61 \\
\hline Mean & & 0.65 & $<0.001$ & 5.9 & 23.7 & \\
\hline
\end{tabular}

(\% Chl- $a$ ) monotonically increases with increasing Chl- $a$ (Fig. 2c), whereas for picoplankton, this monotonically decreases with increasing Chl- $a$ (Fig. 2a). From these data, the microplankton contribution to total $\mathrm{Chl}-a$ ranges between $0-82 \%$ Chl- $a$ and the picoplankton contribution ranges between 7-93\% Chl- $a$, showing large variations in time and/or space. The fractional contribution of nanoplankton does not vary monotonically with Chl- $a$ as found in micro- and picoplankton (Fig. 2b). Rather \% Chl- $a$ of nanoplankton increases as Chl- $a$ increases up to approximately $0.2 \mathrm{mg} \mathrm{m}^{-3}$ but decreases as Chl- $a$ further increases, resulting in a broad maximum between approximately $0.1-0.5 \mathrm{mg} \mathrm{m}^{-3}$. The nanoplankton contribution to total Chl- $a$ ranges from $7-73 \%$ Chl- $a$, showing a smaller range of variation than micro- and picoplankton.

These size-class relationships (micro-, nano-, and picoplankton) are further decomposed into a range of PFTs. Microplankton (Fig. 2c) is subdivided into diatoms and dinoflagellates (Fig. 2f and i), and their abundance ratios vary against Chl- $a$ showing a similar relationship to that of microplankton. Picoplankton is composed of pico-eukaryotes and prokaryotes (Fig. 2d and g), the latter of which include Prochlorococcus sp. (Fig. 2i). The relationships between Chl- $a$ and subtypes within the picoplankton community are not the same. The \% Chl- $a$ of prokaryotes and Prochlorococcus sp. non-monotonically changes with Chl- $a$, with a local maximum at Chl- $a=0.06-0.13 \mathrm{mg} \mathrm{m}^{3}$ (Fig. $2 \mathrm{~g}$ and i). Pico-eukaryotes also show a non-monotonic variation with Chl- $a$ but with a local minimum at $0.08-0.13 \mathrm{mg} \mathrm{Chl}-a \mathrm{~m}^{-3}$, increasing slightly up to $0.70 \mathrm{mg} \mathrm{Chl-} a \mathrm{~m}^{-3}$, then decreasing gradually again above this. Prymnesiophytes (haptophytes) show a similar distribution and magnitude to those of the nanoplankton (Fig. 2e), implying that they are the major group within the nanoplankton community. Green algae also show a broad peak between 0.3 and $0.7 \mathrm{mg} \mathrm{Chl}-a \mathrm{~m}^{-3}$, consistent with the distribution of nanoplankton (Fig. 2h).
The relationships between Chl- $a$ and \% Chl- $a$ shown in Fig. 2 can be quantified using a least square fit (thick solid lines in Fig. 2), enabling the estimation of \% Chl- $a$ of each PFT from Chl- $a$ alone, hence from satellite-derived Chl- $a$ fields (O'Reilly et al., 1998; McClain et al., 2009). Table 2 summarizes the fitting formulae and associated coefficients to quantify the relationship between Chl- $a$ and \% Chl- $a$ for each PFT. The relationships between Chl- $a$ and \% Chl- $a$ of micro- and picoplankton as well as Diatoms were represented using a logistic equation, however, the relationships with other PFTs were not represented by this form. Thus, the use of the logistic growth model for \% Chl- $a$ was only applicable to a limited number of phytoplankton classifications (micro, diatoms and pico) in our data set.

Simple polynomial fitting functions could also have been applied to the quantification of the relationships, however, they tend to over- or underestimate at lower and upper bounds of the Chl- $a$ range observed, without introducing a significant statistical improvement (hence, results not shown). When the simple polynomial fitting is used to extrapolate outside the Chl- $a$ range in Fig. 2, which would be necessary for satellite data processing, they would introduce larger errors than those shown in Table 3. Hence, we did not employ the simple polynomial fitting.

To maintain "mass balance", not all relationships are regressed. For example, \% Chl- $a$ due to nanoplankton is derived from $100-\%$ Chl- $a$ (microplankton) $-\%$ Chl- $a$ (picoplankton) so that micro-, nano- and picoplankton sum up to $100 \%$. The nanoplankton relationship derived in this way (shown as a thin curve in Fig. 2b) still fits the observed data well, reflecting strength in the micro- and picoplankton fits. This subtraction could equally have been undertaken between micro- and nanoplankton derived from regression, or similarly between nano- and picoplankton. However, the best statistical fit was found in our data set when $\% \mathrm{Chl}-a$ (nanoplankton) was not regressed. The method was also 
Table 4. Statistical results of the validation.

\begin{tabular}{lrrccc}
\hline Size Class/PFT & slope & intercept & $r^{2}$ & $p$ & RMSE [\% Chl- $a$ ] \\
\hline Microplankton & 1.109 & 1.073 & 0.72 & $<0.001$ & 8.28 \\
Diatoms & 1.115 & 1.732 & 0.73 & $<0.001$ & 7.98 \\
Dinoflagellates & 0.075 & 3.055 & 0.00 & 0.106 & 1.87 \\
Nanoplankon & 1.168 & -9.721 & 0.56 & $<0.001$ & 8.55 \\
Green algae & 0.809 & 2.035 & 0.40 & $<0.001$ & 4.71 \\
Prymnesiophytes & 1.218 & -8.093 & 0.37 & $<0.001$ & 10.0 \\
(Haptophytes) & & & & & \\
Picoplankton & 1.000 & -0.480 & 0.74 & $<0.001$ & 7.12 \\
Prokaryotes & 0.864 & 3.712 & 0.65 & $<0.001$ & 7.71 \\
Pico-Eukaryotes & 0.801 & 2.564 & 0.31 & $<0.001$ & 5.25 \\
Prochlorococcus sp. & 0.982 & 0.353 & 0.72 & $<0.001$ & 6.25 \\
\hline Mean & 0.914 & -0.377 & 0.52 & $<0.001$ & 5.97 \\
\hline
\end{tabular}

used to derive prymnesiophytes within the nanoplankton, dinoflagellates within the microplankton community and picoeukaryotes within the picoplankton community (see Table 2).

Figure 3 shows the estimated uncertainties of the relationships between \% Chl- $a$ and Chl- $a$, defined here as the residual between in situ data and the least-square fit. The uncertainty varies according to both the PFT considered and the Chl- $a$ level. Maximum mean uncertainty (i.e. maximum Root Mean Square Error, RMSE), is $8.4 \%$ Chl- $a$ for prymnesiophytes (haptophytes, Fig. 3e), while minimum is $2.1 \%$ Chl- $a$ for dinoflagellates (Fig. 3i). The overall mean uncertainty is 5.9\% Chl- $a$ when all PFTs are considered (Table 3). The uncertainty is variable even within a specific PFT considered. For example, for diatoms the local maximum of uncertainty is as high as $+31.8 \%$ Chl- $a$ at Chl- $a$ of $0.49 \mathrm{mg} \mathrm{m}^{-3}$ but $-20 \%$ Chl- $a$ at Chl- $a$ of $1.8 \mathrm{mg} \mathrm{m}^{-3}$ (Fig. 3f; see also Table 3). Thus the regressions obtained in Fig. 2 would represent synoptic relationships between Chl- $a$ and \% Chl- $a$ of each PFT, and small scale variability of PFT, both in time and space, may not be represented well in our proposed formulations.

\subsection{Validation of the relationships between Chl- $a$ and PFTs}

Figure 4 shows validation results and Table 4 summarises its statistical details; the mean regression slope over all PFTs is 0.914 , the intercept -0.377 , the coefficient of determination $r^{2}=0.52$ with RMSE $=5.97 \%$ Chl $-a$. The algorithm performance varies depending on the PFT of interest. While for picoplankton the algorithm performed particularly well $\left(r^{2}=0.74\right.$, Fig. 4a and see also Table 4$)$, for dinoflagellates it performed poorly $\left(r^{2}<0.00\right.$, Fig. 4 i) which resulted in a reduction of the mean $r^{2}$ over all PFTs. Careful examination of results for microplankton (Fig. 4c), diatoms (Fig. 4f) and dinoflagellates (Fig. 4i) suggests that the estimation of large-cell phytoplankton is less accurate when they com- prise $<12 \%$ Chl- $a$ (recall the uncertainties for these PFTs are 6.7, 6.3, 2.1\% Chl- $a$ as shown in Table 3). Nanoplankton (Fig. 4b), prymnesiophytes (haptophytes, Fig. 4e), green algae (Fig. 4h) indicate artificial cut-offs at the higher end of the estimated \% Chl- $a$. This results from the fact that (1) the relationships between Chl- $a$ and \% Chl- $a$ of PFTs are formulated by the least-square regression, so that a single value of Chl- $a$ returns a single value of \% Chl- $a$ and (2) the functional forms of the relationships for these particular PFTs show a local maxima which is also the maximum over the given range of Chl- $a$, thus does not allow to return \% Chl$a$ above the maximal value; for example, see Fig. $2 b$ where the reconstructed curve takes the unique maximal value of $\% \mathrm{Chl}-a$ at Chl- $a$ of $0.20 \mathrm{mg} \mathrm{m}^{-3}$, which is also the maximum value over the entire Chl- $a$ range, while \% Chl- $a$ in the in situ data fluctuates around the same Chl- $a$ value of $0.20 \mathrm{mg} \mathrm{m}^{-3}$ (approx. 35-62 \% Chl-a).

\subsection{Global distribution of PSCs/PFTs}

Figure 5 shows the global mean distributions of each PFT, derived from SeaWiFS Chl- $a$ observed over the period 19982009. Dinoflagellates are not considered here due to a poor result in the validation. Microplankton is relatively abundant at mid and high latitudes (Fig. 5a). Microplanktondominated waters (e.g. \% Chl- $a>50 \%$ ) are rather restricted along some parts of the Arctic and Antarctic coasts and coastal upwelling regions such as the Benguela, Humbolt, California and Canary current regions. Thus, microplankton, which are almost entirely composed of diatoms at the synoptic scale (Fig. 5d), do not show a basin-scale spatial dominance within the phytoplankton community in the mean field over 1998-2009. Nanoplankton is ubiquitously distributed, and constitutes a background population contributing approximately $45.5 \% \mathrm{Chl}-a$ as a global mean, but less in the subtropical gyres (Fig. 5b). Prymnesiophytes (haptophytes) comprise the major group in the nanoplankton 

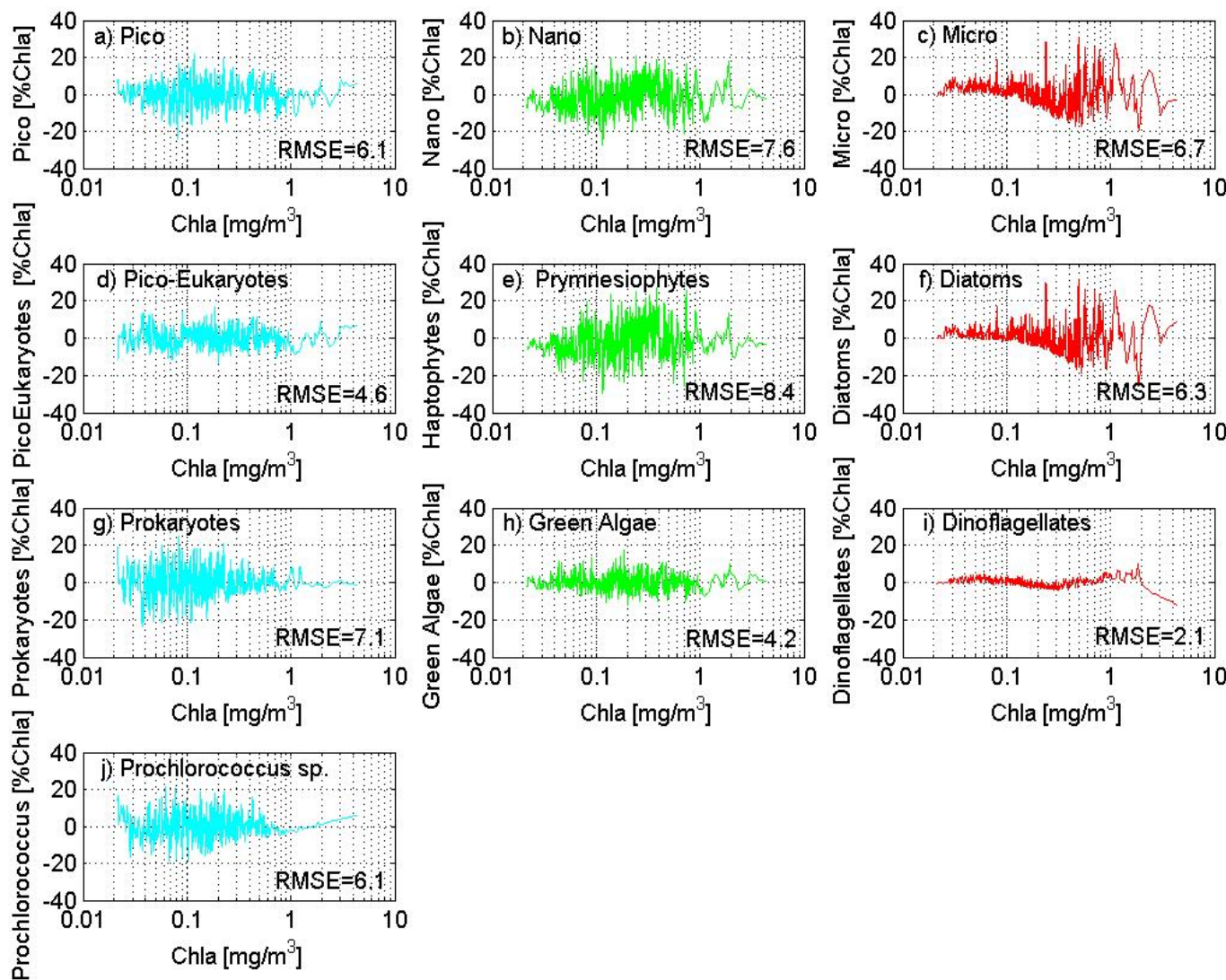

Chla $\left[\mathrm{mg} / \mathrm{m}^{3}\right]$

Fig. 3. Uncertainties of the synoptic relationships between Chl- $a$ and $\%$ Chl- $a$ of each PFT, i.e. $\left(X_{\mathrm{obs}}-X_{\mathrm{fit}}\right)$ where $\mathrm{X}_{\mathrm{obs}}$ and $\mathrm{X}_{\mathrm{fit}}$ represent $\%$ Chl- $a$ observed or fitted for each PFT and PSC, respectively; (a) Picoplankton, (b) Nanoplankton, (c) Microplankton, (d) Pico-eukaryotes, (e) Prymnesiophytes (Haptophyotes), (f) Diatoms, (g) Prokaryotes, (h) Green algae, (i) Dinoflagellates, (j) Prochlorococcus sp. The root mean square error, RMSE (\% Chl- $a$ ), is also calculated by SQRT $\left\{\Sigma\left(\mathrm{X}_{\mathrm{obs}}-\mathrm{X}_{\mathrm{fit}}\right)^{2} / \mathrm{n}\right\}$ where $\mathrm{n}$ represents the number of data.

(Fig. 5e), explaining $31.7 \% \mathrm{Chl}-a$ and $70 \%$ of the nanoplankton $\%$ Chl- $a$. The results obtained in this study are consistent with those of Liu et al. (2009) who found that prymnesiophytes (haptophytes) dominate the Chl- $a$-normalized phytoplankton stock in modern oceans. The subtropical gyres are largely dominated by picoplankton (\% Chl- $a>65 \%$, Fig. 5c), mostly by prokaryotes (Fig. 5h) which include Prochlorococcus sp. (Fig. 5i). In the South Pacific gyre, pico-eukaryotes constitute a significant proportion (up to $37 \%$ Chl- $a$, Fig. $5 \mathrm{~g}$ ), along with prokaryotes, which may be supported by the in situ data analysis of Ras et al. (2008) who postulate a possible significance of pico-sized flagellates (i.e. pico-eukaryotes) in the South Pacific Ocean, especially at the surface. On average over the 1998-2009 period, microplankton, nanoplankton and picoplankton explain 10.9, 45.5 and $43.6 \%$ Chl- $a$ respectively of global surface Chl- $a$, whereas diatoms, green algae, pico-eukaryotes, prokaryotes and Prochlorococcus sp. explain approximately 7.5, 13.8, $17.2,26.5$ and $22.8 \%$ Chl- $a$, respectively.

Figure 6 shows the global map of mean maximum uncertainty in the algorithm, estimated for the PSCs/PFTs in the following way: (1) 7 ocean biomes were defined according to the method of Hardman-Mountford et al. (2008); (2) the absolute deviations (residuals) between the PSCs/PFTs estimated $\left(\mathrm{PFT}_{\text {est }}\right)$ and observed $\left(\mathrm{PFT}_{\mathrm{obs}}\right)$ shown earlier, i.e. $\mathrm{PFT}_{\text {est }}-\mathrm{PFT}_{\mathrm{obs}}$, were classified geographically using latitude and longitude associated with the observed data, and assigned to an ocean biome; (3) the residuals within each biome were averaged and the mean uncertainty was calculated for each biome, then mapped globally. The global uncertainty shows a relatively large uncertainty of $>+35 \%$ for microplankton and diatoms at high latitudes and in the eastern boundary upwelling regions. Uncertainty in the subtropical gyres of the South Pacific is approximately $+22 \%$ for nanoplankton and $-8 \%$ for picoplankton. This inverted bias for nano- and picoplankton in the South Pacific is due to the maintenance of mass balance between these PSCs. While uncertainties for other PFTs are rather small $(< \pm 5 \%)$, a relatively large uncertainty is found for prymnesiophytes in tropical oceans $(-25 \%)$. It is important to note that uncertainty of Chl- $a$, which is an input to the present estimation of PSCs/PFTs, should be added to obtain an overall uncertainty 

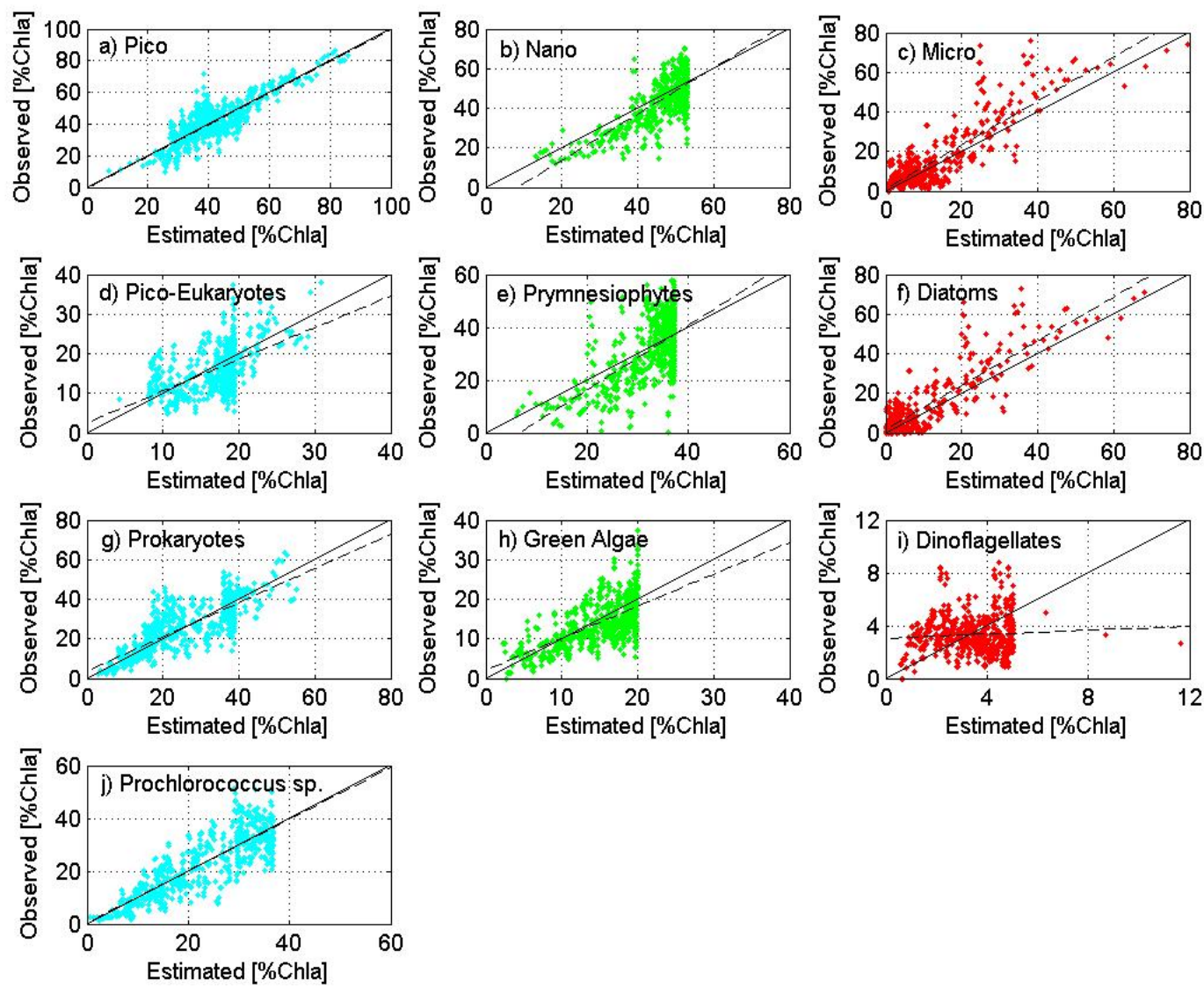

Fig. 4. Results of validation; (a) Picoplankton, (b) Nanoplankton, (c) Microplankton, (d) Pico-eukaryotes, (e)) Prymnesiophytes (Haptophyotes), (f) Diatoms, (g) Prokaryotes, (h) Green algae, (i) Dinoflagellates, (j) Prochlorococcus sp. The root mean square error, RMSE $(\%$ Chl $-a)$, is also calculated by SQRT $\left\{\Sigma\left(\mathrm{X}_{\mathrm{obs}}-\mathrm{X}_{\mathrm{fit}}\right)^{2} / \mathrm{n}\right\}$ where $n$ represents the number of data. See Table 4 for statistical details.

for the derivation of PSCs/PFTs from space.

Figure 7 shows the global distribution of PFTs as in Fig. 5 but in terms of Chl- $a$ with the unit of $\mathrm{mg} \mathrm{m}^{-3}$ rather than \% Chl- $a$. Microplankton (Fig. 7a) is rather limited to marginal seas and coastal upwelling regions but mean Chl$a$ is as high as $\sim 0.11 \mathrm{mg} \mathrm{m}^{-3}$ on average over the globe and the 1998-2009 period. Nano- and picoplankton are relatively wide-spread over the globe (Fig. $7 \mathrm{~b}$ and c). Nanoplankton $\left(\sim 0.12 \mathrm{mg} \mathrm{m}^{-3}\right)$ is abundant in the mid and high latitude and largely explained by prymnesiophytes (haptophytes) $\left(\sim 0.08 \mathrm{mg} \mathrm{m}^{-3}\right)$, showing the relatively high global mean Chl- $a$ comparable to microplankton. This implies a large role of nanoplankton in primary production in the global surface oceans as well as microplankton. Picoplankton (global average of $\sim 0.08 \mathrm{mg} \mathrm{m}^{-3}$ ) is also wide spread but more abundant in the subtropical gyres (Fig. 7c). Although small phytoplankton such as pico-eukaryotes, prokaryotes and Prochlororoccus sp. were shown to have relatively high $\%$ Chl- $a$ in the subtropical gyres (Fig. 5g, h and i), their absolute Chl- $a$ abundance (Fig. 7g, h and i) is relatively low ( $\sim 0.04, \sim 0.04$ and $\sim 0.03 \mathrm{mg} \mathrm{m}^{-3}$, respectively), as the Chl$a$ of the total phytoplankton community is low in these re- gions. Green algae (Fig. 6f) and pico-eukaryotes (Fig. 6g) show a similar global distribution and mean Chl- $a$ value $\left(\sim 0.04 \mathrm{mg} \mathrm{m}^{-3}\right)$ to each other, although they are notably different in \% Chl- $a$ (Fig. $5 f$ and g).

\subsection{Seasonal variations of PSCs/PFTs}

Along with the characteristic spatial distributions shown, strong seasonality in the composition of the phytoplankton community is exhibited for each ocean basin, clearly shown in the monthly climatologies (Fig. 8). In the Northern Hemisphere (Fig. 8a, c, e), the spring bloom of microplankton and diatoms in May is obvious, which is reflected in the global average (Fig. 8h). A characteristic second bloom is also seen in the North Pacific (Fig. 8e). Apart from the Southern Ocean (Fig. 8b), less remarkable blooms are found in September to December in the Southern Hemisphere (Fig. 8d, $\mathrm{f}$ and g), the amplitude of which varies between regions and according to PSCs/PFTs. A relatively large bloom is found in December for the Southern Ocean and the South Atlantic (Fig. 8b and d), whereas an increase in Chl- $a$ is found in September to November for the South Pacific and the Indian Ocean (Fig. $8 \mathrm{f}$ 
a) Micro

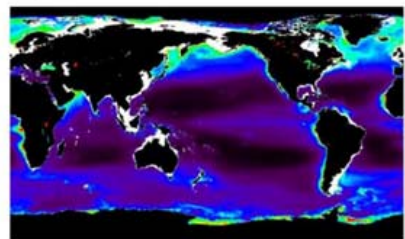

d) Diatoms

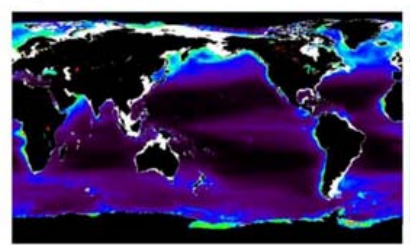

g) Pico-Euraryotes

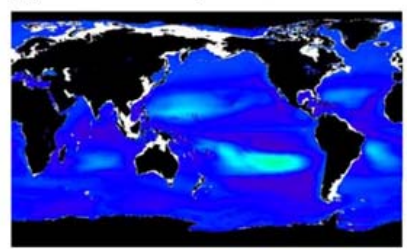

b) Nano

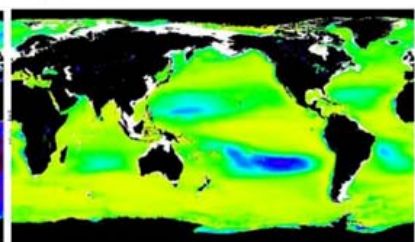

e) Prymnesiophytes

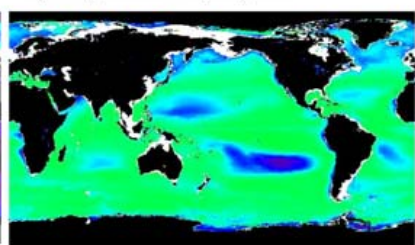

h)Prokaryotes

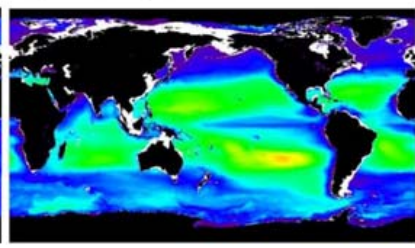

c) Pico

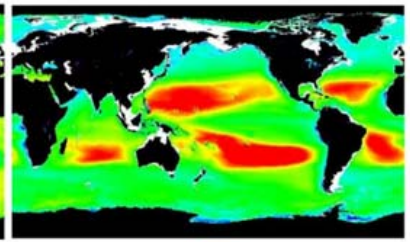

f) Green Algae

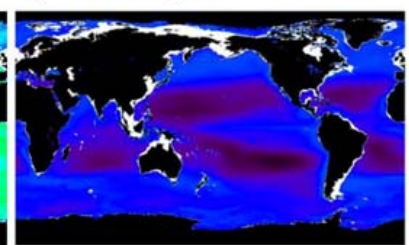

i) Prochlorococcus sp.

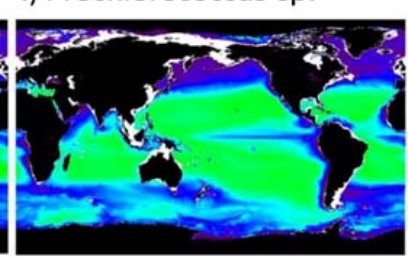

\section{$>70$
60}

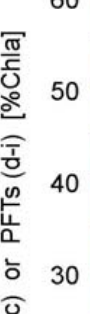

20

10

0

Fig. 5. Synoptic distribution of surface PFTs [\% Chl- $a$ ] over 1998-2009 derived from SeaWiFS. (a) Microplankton (global average $\sim 10.9 \%$ Chl- $a$ ), (b) Nanoplankton ( 45.5\% Chl- $a$ ), (c) Picoplankton ( 43.6\% Chl- $a$ ), (d) Diatoms ( 7.5\% Chl- $a)$, (e) Green Algae ( 13.8\% Chl-a), (f) Pico-eukaryotes ( 17.2\% Chl- $a$ ), (g) Prymnesiophytes (Haptophytes) ( 31.7\% Chl- $a$ ), (h) Prokaryotes ( 26.5\% Chl- $a$ ), (i) Prochlorococcus sp. $(\sim 22.8 \% \mathrm{Chl}-a)$. White area shows a continental shelf mask defined by $<200 \mathrm{~m}$.
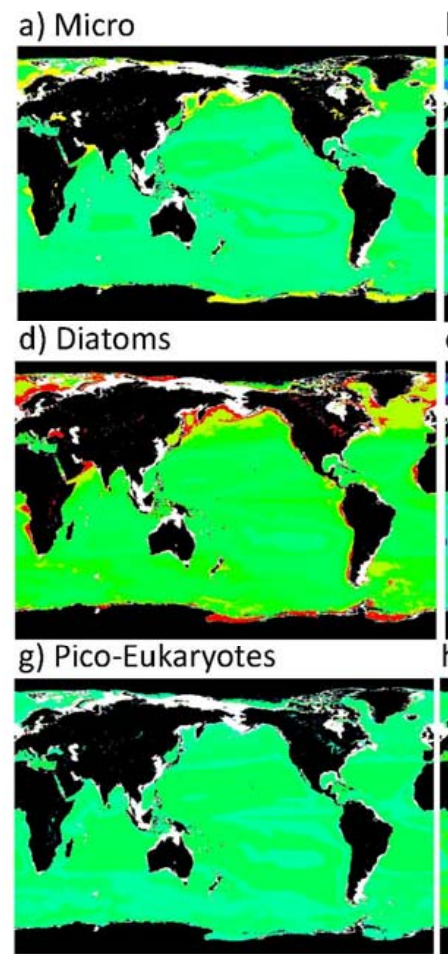

b) Nano

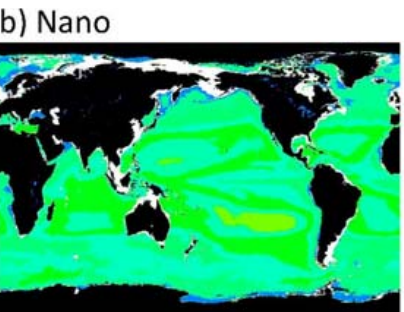

e) Prymnesiophytes

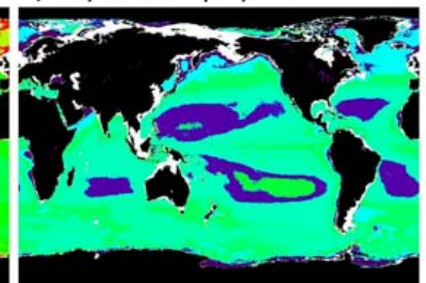

h)Prokaryotes

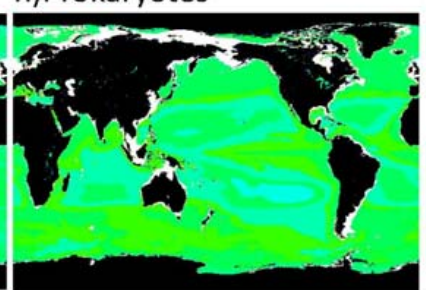

c) Pico

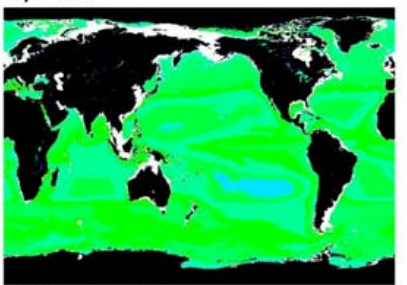

f) Green Algae

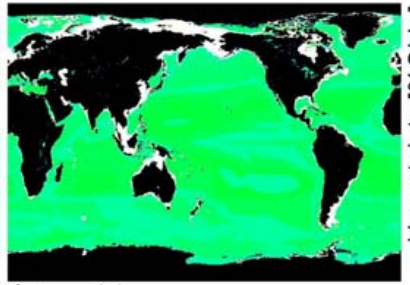

i) Prochlorococcus sp.

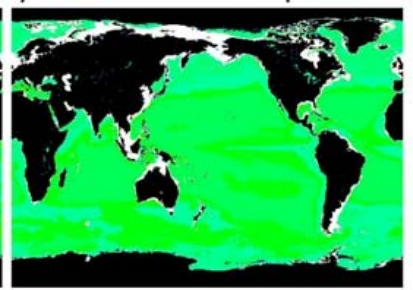

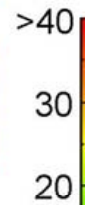

20

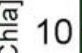

亮

$-30$

$<-40$

Fig. 6. Spatial distribution of uncertainty in the algorithm estimated for PSCs (a-c) and PFTs (d-h); (a) Microplankton, (b) Nanoplankton, (c) Picoplankton, (d) Diatoms, (e) Prymnesiophytes, (f) Green algae, (g) Pico-Eukaryotes, (h) Prokaryotes, (i) Prochlorococcus sp. 
a) Micro

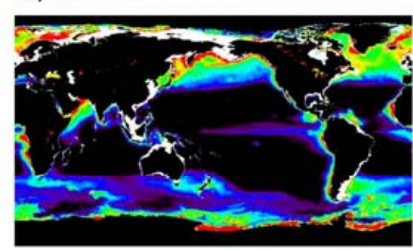

d) Diatoms

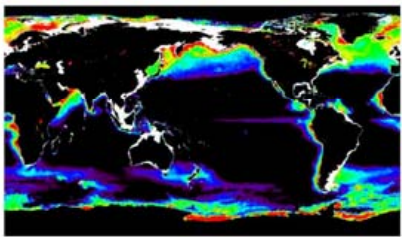

g) Pico-Eukaryotes

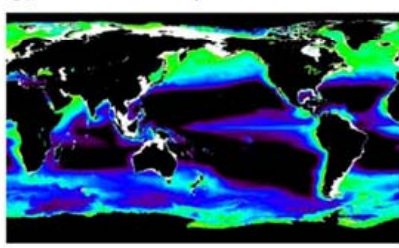

b) Nano

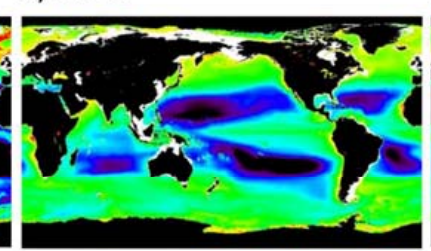

e) Prymnesiophytes

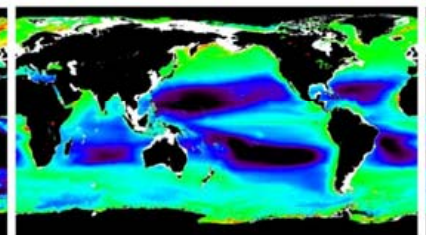

h) Prokaryotes

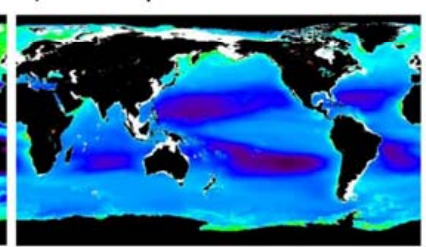

c) Pico

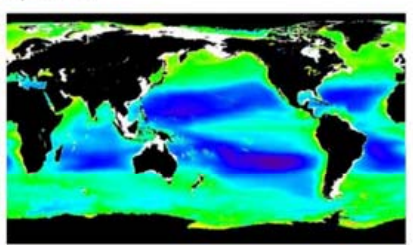

f) Green Algae

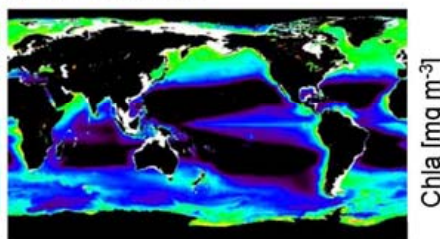

i) Prochlorococcus sp.

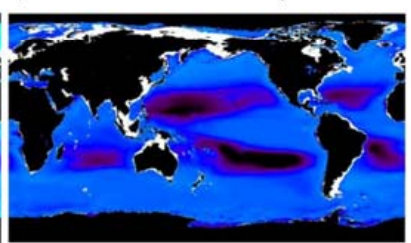

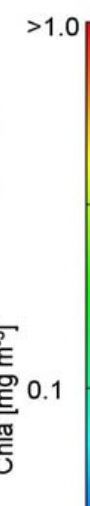

0.01

Fig. 7. Synoptic distribution of mean surface Chl- $a\left(\mathrm{mg} \mathrm{m}^{-3}\right)$ of PSCs (a-c) and PFTs (d-i) over 1998-2009 derived from SeaWiFS; (a) Microplankton (global average $\left.\sim 0.11 \mathrm{mg} \mathrm{m}^{-3}\right)$, (b) Nanoplankton $\left(0.12 \mathrm{mg} \mathrm{m}^{-3}\right)$, (c) Picoplankton $\left(0.08 \mathrm{mg} \mathrm{m}^{-3}\right)$, (d) Diatoms $\left(0.09 \mathrm{mg} \mathrm{m}^{-3}\right)$, (e) Green Algae $\left(0.04 \mathrm{mg} \mathrm{m}^{-3}\right)$, (f) Pico-eukaryotes $\left(0.04 \mathrm{mg} \mathrm{m}^{-3}\right)$, (g) Prymnesiophytes $($ Haptophytes $)\left(0.08 \mathrm{mg} \mathrm{m}^{-3}\right),(\mathbf{h})$ Prokaryotes $\left(0.04 \mathrm{mg} \mathrm{m}^{-3}\right)$, (i) Prochlorococcus sp. $\left(0.03 \mathrm{mg} \mathrm{m}^{-3}\right)$. White area shows a continental shelf mask defined by $<200 \mathrm{~m}$.

and g). Variability in bloom timing between PSCs/PFTs suggests taxonomic succession. This is relatively clear even in the basin scale for the North Pacific and the Indian Ocean (Fig. 8e and g), where an increase in nano/picoplankton precedes the onset of the microplankton (diatom) bloom.

\section{Comparison with other approaches}

Figure 9 shows comparisons between PSCs estimated by the present study with existing methods (Uitz et al., 2006; Brewin et al., 2010). PFTs are not compared since there is currently no other method available to derives 7 PFTs, neither in $\%$ Chl- $a$ nor $\mathrm{mg} \mathrm{m}^{-3}$. For microplankton, this study gives a reduced estimate of their contribution (approx. $-6 \%$ Chl-a) compared to both Uitz et al. (2006) and Brewin et al. (2010) (Fig. 9a and b, respectively) in the majority of the ocean but an increased estimate of their contribution in the higher chlorophyll regions around ocean margins and in the temperate North Atlantic (up to approx. 21\% Chl$a)$; note that the comparison is undertaken during the boreal spring bloom period. These differences are explained by the application of a fucoxanthin correction to the DPA in the present study to improve discrimination of diatoms from prymnesiophytes (haptophytes) (as described above). The differences at higher Chl- $a$ might also result from the fact that different data sets were used to parameterize each method.

The spatial pattern of differences in nanoplankton also reflects this adjustment, with this study showing an increase in nanoplankton \% Chl- $a$. A further contribution to the increased estimation of nanoplankton by the present method results from the treatment of Chlorophyll- $b$ (Chl- $b)$ in the DPA. In the present analysis, Chl- $b$ was used in the definition of nanoplankton, whereas it was used to define picoplankton in the previous methods. The rationale for the treatment of Chl- $b$ as a biomarker contributing to nanoplankton in this work is as follows; (i) Fig. 2 shows that the predominant occurrence of green algae, for which Chl- $b$ is the diagnostic marker pigment (Table 1), occurs at Chl- $a>0.2 \mathrm{mg} \mathrm{m}^{-3}$ where Prochlorococcus sp., which contains divinyl Chl- $b$ $(\mathrm{dvChl}-b)$ as well as divinyl Chl- $a$ and is defined independently from nanoplankton in our DPA, show a progressive decline (as seen in Fig. 2h). Therefore, Chl- $b$ is largely representative of monovinyl Chl- $b$ (mvChl- $b$ ) in our data set, (ii) The Chl- $a$ value of $0.20-0.25 \mathrm{mg} \mathrm{m}^{-3}$ geographically corresponds to the border of the region of the subtropical gyres (Polovina et al., 2001; Aiken et al., 2009) where Prochlorococcus sp. becomes less dominant. Thus, our approach is the first to mechanistically consider separation of mono- and divinyl Chl- $b$ in the DPA and the global distribution of Chl- $b$ vs. Chl- $a$ used for the regression (Fig. 2e) justifies the use of mvChl- $b$ in the nano range, providing an improvement over 

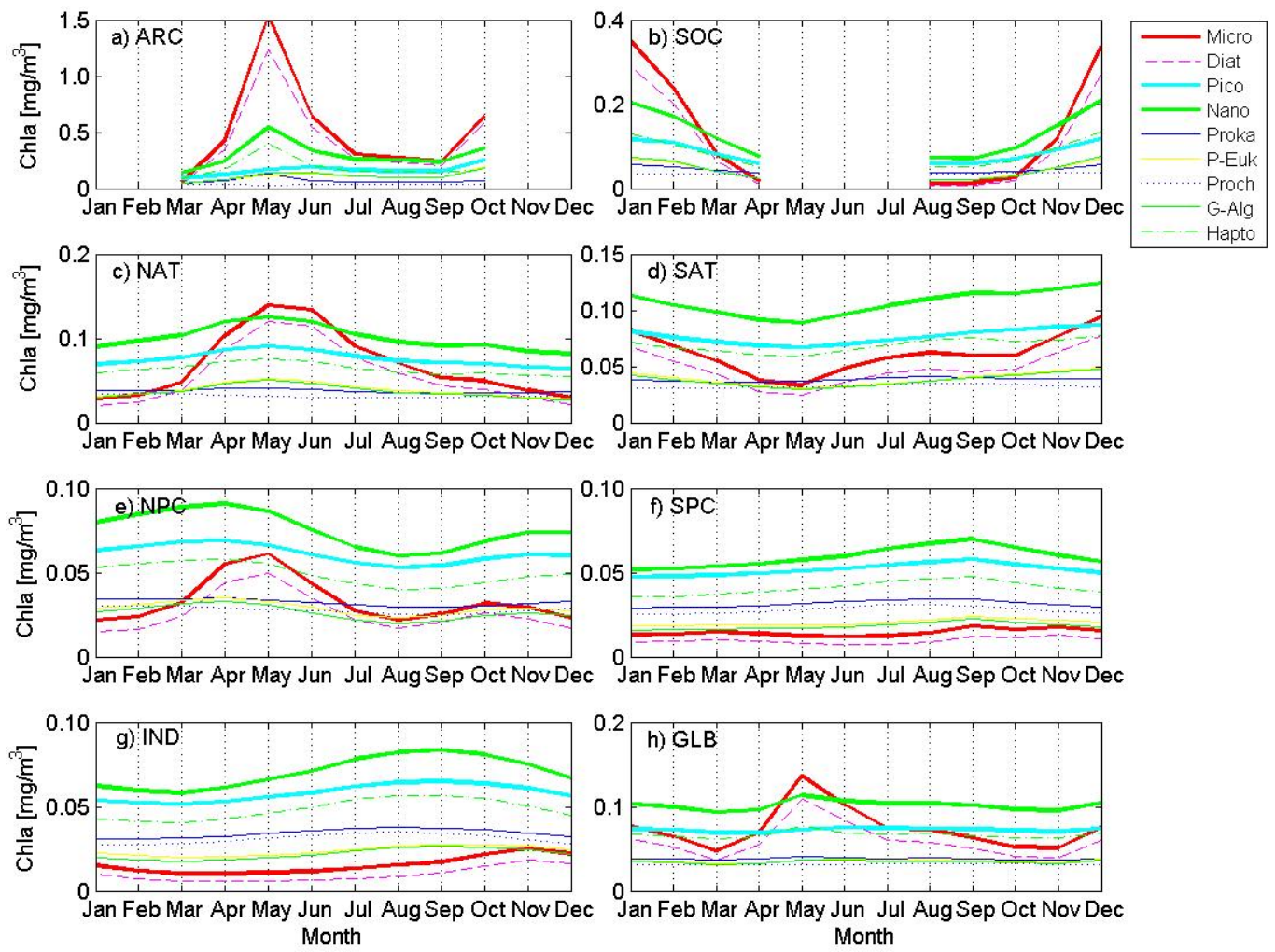

Fig. 8. Monthly climatology of each PSC and PFT derived from SeaWiFS satellite chla over 1998-2009: (a) the Arctic Ocean (ARC), (b) the Southern Ocean (SOC), (c) the North Atlantic (NAT), (d) the South Atlantic (SAT), (e) the North Pacific (NPC), (f) the South Pacific (SPC), (g) the Indian Ocean (IND), (h) the Global Oceans (GLB). For the Arctic and Southern Oceans, the satellite Chl- $a$ is not available for winter period.

improvement over the previous studies. A future improvement would be to add a pico-eukaryote adjustment to mvChl$b$ as we have for Hex. Care also needs to be taken at very low Chl- $b$ concentrations where discrimination of mvChl- $b$ and $\mathrm{dvChl}-b$ is less reliable, possibly contributing another source of uncertainty.

A further difference in the nanoplankton is seen in the subtropical gyre regions with the present study giving much lower estimates than Uitz et al. (2006), particularly in the South Pacific (Fig. 9.a.2 and 9.b.2). The inverse difference is seen in the picoplankton, with the present study giving higher estimates than Uitz et al. (2006), reflecting the mass-balance applied in our analysis (i.e. micro + nano + pico $=100 \%$ ). In both cases, differences with Brewin et al. (2010) are far less marked. These differences are explained by the application of a pico-eukaryote correction in this study and by Brewin et al. (2010) but not by Uitz et al. (2006). The correction adjusts the picoplankton by partitioning the diagnostic marker pigment Hex to account for prymnesiophytes (haptophytes) within both the nano and the pico size domains separately, reducing the contribution to nanoplankton and increasing the contribution to picoplankton at low Chl- $a$. The smaller differences between Brewin et al. (2010) and this study at very low Chl- $a$ may be due to acceleration in the regression slopes derived by this study when extrapolated below $0.03 \mathrm{mg} \mathrm{m}^{-3}$.

\section{Discussion}

Monthly climatologies show intensive blooms of microplankton and diatoms to occur but only at specific periods throughout the year (Fig. 8). Recalling that their spatial distributions are limited to coastal and some parts of mid and high latitudes (Fig. 5a and d), microplankton and diatoms can be dominant only at a localized scale, both spatially and temporally, rather than as a background group at the synoptic scale. Supporting this global view of microplankton and diatom distributions, Obayashi et al. (2001) suggested for the subarctic North Pacific that an ubiquitous basic structure made up of a diverse population was apparent, on which a flourishing diatom population, limited by area and season, was superimposed sporadically. However, a number of patches dominated by microplankton or diatoms can also be found in open oceans, especially in the Southern Ocean (Fig. 7a). These patches may be associated with turbulent flows such as eddies, and be captured by ship observation 
(a) This Study - Uitz et al. (2006)
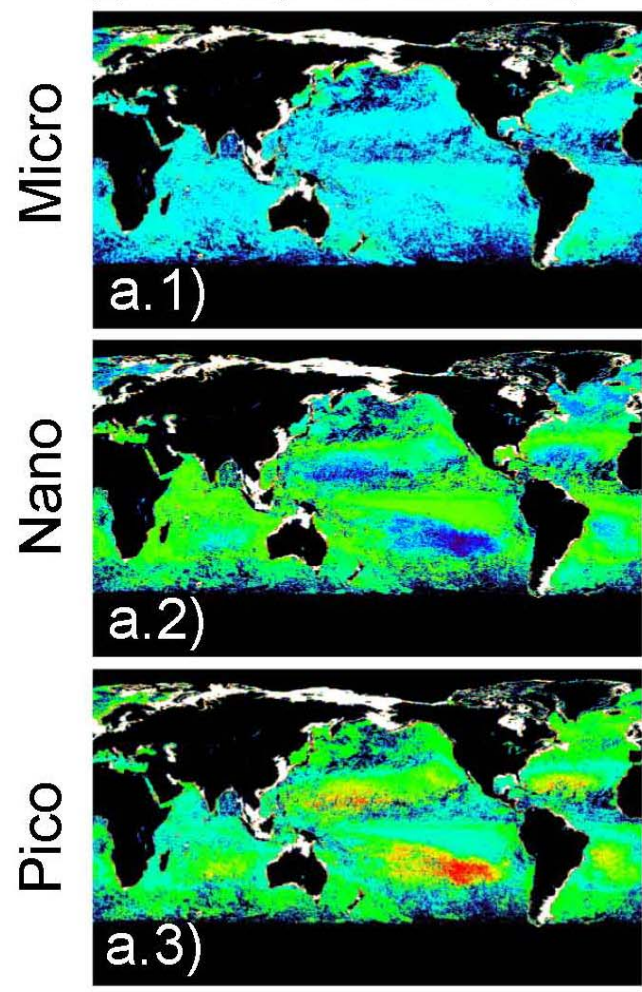

(b)This study - Brewin et al.(2010)

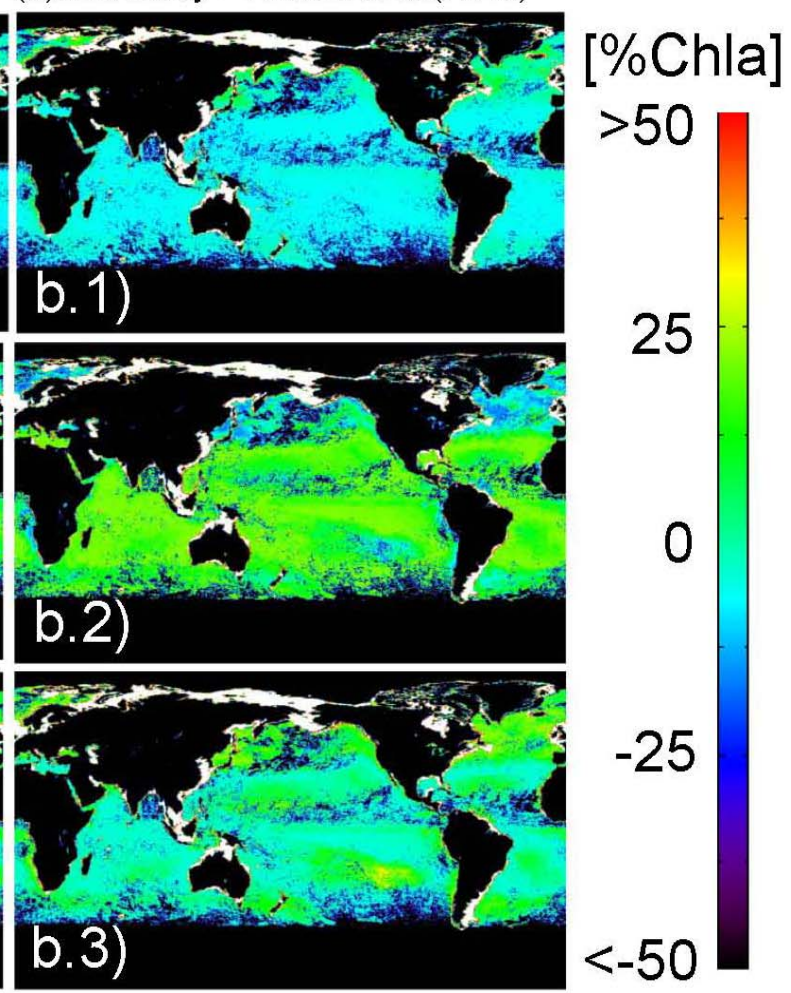

Fig. 9. Absolute deviation of PSCs in Chl- $a\left(\mathrm{mg} \mathrm{m}^{-3}\right)$ between this study and Uitz et al. (2006) as well as between this study and Brewin et al. (2010) for May 2005.

even if the observation is usually limited in temporal and spatial coverage.

The high levels of Prochlorococcus sp. predicted to occur in the Southern Ocean by the present study are outside the known distribution range for this organism and most likely an anomaly caused by extrapolation from in situ samples taken in areas where the Prochlorococcus signal is strong to areas where there are few or no Prochlorococcus sp. but where similar chlorophyll- $a$ levels occur. This is a fundamental undersampling issue and requires in situ data to identify what replaces Prochlorococcus sp. in these ecosystems to correct the present algorithm. Known problems with remote sensing algorithms for Chl- $a$ at higher latitudes may also contribute to this anomaly. The dominance of Prochlorococcus sp. in the gyres is consistent with observations (Zwirglmaier et al., 2007, 2008; Grob et al., 2007). The low contribution of other prokaryotes, which are most likely repesented by Synechococcus sp. in the gyres, is consistent with the orders of magnitude lower number of cells for this organism in these regions and its reduced dependence on chlorophyll- $a$ as a photosynthetic pigment, instead using phycoerythrin as well.
The spatial distribution and temporal variation of PFTs captured by SeaWiFS are based on the empirical relationships between Chl- $a$ and PFTs obtained from in situ data collected at various times of the year in the global surface oceans. While the derived relationships reasonably reproduced the PFT structure within the time span of the data (1995-2008) as shown in Fig. 4, an extrapolation of the relationships to future satellite observations may introduce an ambiguity between possible real natural fluctuations of the PFTs and a potential drift of the empirical relationships from reality. When the relationships are viewed as algorithms to estimate the PFTs from satellite, ongoing re-calibration of the algorithm may be required over time to reduce any such ambiguity. Furthermore, it is currently unknown whether or not an unexpected shift in PSC/PFT composition in marine ecosystems can be detected by the present method over the period analyzed, for which it is well-calibrated. Our global in situ data collected over 1995-2008 showed that a variation of PSCs/PFTs at the synoptic scale is reflected, or accompany, a change in Chl- $a$ in a complex marine ecosystem. Further investigation is needed to investigate, perhaps in a probabilistic sense, if an unexpected abrupt change of PSCs/PFTs could occur independently of a change in Chl- $a$, thereby remaining undetected by the algorithm. This contrasts with a gradual 
shift in the community composition to Chl- $a$ relationship, which could be recalibrated.

The results presented in this work are limited to the surface ocean and global applications. Caution must be taken when the relationships are applied to analysis for smaller scales, in space or time (i.e. within a narrower Chl- $a$ range), because an increased noise-to-signal ratio in the relationships is expected from Fig. 2. Fluctuations of \% Chl- $a$ (or variability along y-axis in Fig. 2) for a restricted range of Chl- $a$ can become significantly large relative to the variability of Chl- $a$ itself (or variability along $\mathrm{x}$-axis), which may result in a degraded relationship between Chl- $a$ and \% Chl- $a$ for each PFT in that Chl- $a$ range. Such a fluctuation of \% Chl$a$ at a given Chl- $a$ value could partly result from a temporal variation in phytoplankton community structure at a given geographical point, and partly from geographical spread of data points where the community composition is not necessarily the same. The mathematical representation within the ecological ambiguity is a limitation of the present approach. The data used to quantify the relationships, or to develop the algorithms, should ideally include sampling during pre- to post bloom periods for all ocean basins, providing a greater degree of confidence in the relationships. Continuous accumulation of in situ data to build such a data set would also enable a regular ongoing calibration of the relationships, improving detection of variability in PFTs at smaller temporal and spatial scales.

Physiological changes in the phytoplankton due to environmental changes may also be reflected in the natural variability of the relationships. While laboratory studies show phytoplankton pigment ratios to vary with environmental stimuli (nutrient forcing, light climate), for in situ studies a much clearer relationship between phytoplankton community structure and pigment composition exists. Specifically, the ratio of Chl- $a$ to accessory pigments co-varies with the abundance of different phytoplankton functional types (Fishwick et al., 2006; Aiken et al., 2007, 2008; Hirata et al., 2008). Thus, shifts in phytoplankton community composition rather than acclimation tend to dominate variability in surface oceanic pigment relationships. For example, iron enrichment experiments have shown an increase in Chl- $a$ to be associated with a shift towards larger size classes (e.g. Gall et al., 2001). The link between phytoplankton-type specific Chl- $a$ and carbon (both particulate organic and living carbon) is less well parameterized so care must be taken when converting between these different biomass measures. Nonetheless, physiological changes in the phytoplankton due to environmental changes may necessitate a regular recalibration of the PFT-Chl- $a$ relationship over time.

While other techniques for classification and quantification of PSCs/PFTs, such as flow-cytometric analysis and microscopic analysis, may be available, diagnostic pigment analysis (Vidussi et al., 2001; Uitz et al., 2006; Hirata et al., 2008; Brewin et al., 2010) has been used in this work due to the wide availability of HPLC pigment data. If PSCs/PFTs classified using other techniques were applied to validate the present method, a deviation may be found due to inherent uncertainties between these different methods. This uncertainty is likely to be enhanced in coastal environments where definitions of biomarker pigments may become less robust due to, for example, increased populations of dinoflagellates and colonial Phaeocystis blooms, which can both also contain Fuco (Wright and Jeffrey, 2006), confusing the interpretation of the Fuco signal which is defined in this work as a biomarker pigment for diatoms. Thus, a further correction to diagnostic pigment analysis may be required. There are alternative methods available for classification and quantification of phytoplankton (such as particle counting, microscopic and flow-cytometric analysis), but they also have their own practical and technical difficulties in analyzing natural samples: microscopy requires too much time to complete cell counting and species identification to obtain statistical significance of classification and quantification of phytoplankton at the global scale; particle counters count not only the number of phytoplankton but also any other suspended particles, so require the application of another technique for phytoplankton classification; Flow-cytometers may not size particles well for a wide range of size while counting due to the optical method employed, and they require a priori knowledge of phytoplankton composition within the water sample for classification or identification of phytoplankton. More extensive inter-comparison of cell classification and quantification results from these different methods would be useful to further understand uncertainties associated with both DPA and the present algorithm.

An extensive comparison of several bio-optical algorithms to classify PSCs dominating in seawater, rather than in $\%$ Chl- $a$ or mgChl- $a \mathrm{~m}^{-3}$ of each PSC, has been conducted by Brewin et al. (2011). It showed that abundance-based approaches using Chl- $a$, or its optical analogue such as the absorption coefficient at $443 \mathrm{~nm}$, may be more robust than spectral-response approaches that use either the spectral shape of the absorption coefficient of phytoplankton or the second order variability in the remotely-sensed spectral radiance. However, the spectral-response approaches did perform with similar accuracy and may require less recalibration than the abundance-based approaches regarding long-term trend applications. Since a change in the abundance of Chl- $a$, or its optical analogue, often accompanies a change in the spectral shape (of the absorption coefficient of phytoplankton or the remotely-sensed radiance), the spectral-response and abundance-based approaches are probably inter-related. Continuous exploitation and improvement of both approaches are required for the global observation of PFTs. 


\section{Conclusions}

The synoptic relationships between Chl- $a$ and its fractional contribution from three PSCs and seven PFTs were presented for the first time using a global in situ data set of pigment measurements. It was found that variation in the phytoplankton community structure is not independent of the variation in Chl- $a$ of the total community at large scales. The relationships and their associated uncertainties were quantified and validated to enable global estimation of the PSCs/PFTs from satellite Chl- $a$. The present work revealed global distributions of the detailed structure of dynamic phytoplankton communities within the marine ecosystem, through the description of multiple PFTs, in terms of both percentage and fractional Chl- $a$, derived from satellite ocean colour measurements.

Acknowledgements. Satellite ocean colour data (Sea-viewing Wide Field-of-view Sensor, SeaWiFS) were obtained from NASA Goddard Space Flight Centre. This study was supported by the UK Natural Environment Research Council through the UK marine research institutes strategic research programme Oceans 2025 awarded to Plymouth Marine Laboratory and the National Oceanography Centre, Southampton. This is contribution number 199 of the AMT programme. The authors also would like to acknowledge NASA for, and all individuals and organisations that have contributed to, the SeaWiFS Bio-optical archive and Storage System (SeaBASS) and bio-Optical Marine Algorithm Dataset (NOMAD). This research is funded by the National Centre for Earth Observation (NCEO) through the Natural Environment Research Council (UK) and the Global Climate Observation Mission (GCOM) by JAXA (Japan).

Edited by: E. Marañón

\section{References}

Aita, M. N., Yamanaka, Y., and Kishi, M.: Interdecadal variation of the lower trophic ecosystem in the northern Pacific between 1948 and 2002, in a 3-D implementation of the NEMURO model, Ecol. Model., 202, 81-94, 2007.

Aiken, J., Fishwick, J., Lavender, S., Barlow, R., Moore, G. F., Sessions, H., Bernard, S., Ras, J., and Hardman-Mountford, N.: Validation of MERIS reflectance and chlorophyll during the BENCAL cruise October 2002: preliminary validation of new demonstration products for phytoplankton functional types and photosynthetic parameters, Int. J. Remote Sensing, 28, 497-516, 2007.

Aiken, J., Hardman-Mountford, N. J., Barlow, R., Fishwick, J., Hirata, T., and Smyth, T.: Functional links between bioenergetics and bio-optical traits of phytoplankton taxonomic groups: an overreaching hytpothesis with application for ocean colour remote sensing, J. Phytoplankton Res., 30, 165-181, 2008.

Aiken, J., Pradhan, Y., Barlow, R., Lavender, S., Poulton, A., Holligan, P., and Hardman-Mountford, N. J.: Phytoplankton pigments and functional types in the Atlantic Ocean: a decadal assessment, 1995-2005, Deep Sea Res. Pt. II, 56, 899-917, 2009.

Allen, J., Aiken, J., Anderson, T. R., Buitenuis, E., Cornell, S., Geider, R. J., Haines, K., Hirata, T., Holt, J., LeQuéré, C., Hardman-
Mountford, N. J., Ross, O. N., Sinha, B., and While, J.: Marine ecosystem models for earth systems applications: The MarQUEST experience, J. Mar. Syst., 81, 19-33, 2010.

Alvain, S., Moulin, C., Dandonneau, Y., and Breon, F. M.: Remote sensing of phytoplankton groups in case 1 waters from global SeaWiFS imagery, Deep Sea Res. Pt. I, 1(52), 1989-2004, 2005.

Alvain, S., Moulin, C., Dandonneau, Y., and Loisel, H., Seasonal distribution and succession of dominant phytoplankton groups in the global ocean: A satellite view, Glob. Biogeochem. Cy., 22, GB3001, doi:10.1029/2007GB003154, 2008.

Barlow, R., Stuart, V., Lutz, V., Sessions, H., Sathyendranath, S., Platt, T, Kyewalyanga, M., Clementson, L., Fukasawa, M., Watanabe, S., and Devred, E.: Seasonal pigment patterns of surface phytoplankton in the subtropical southern hemisphere, Deep Sea Res. Pt. I, 54, 1687-1703, 2007.

Behrenfeld, M. J. and Falkowski, P. G.: Photosynthetic rates derived from satellite-based chlorophyll concentration, Limnol. Oceanogr., 42, 1-20, 1997.

Blackford, J., Allen, J. I., and Gilbert, F.: Ecosystem dynamics at six contrasting sites: A generic modelling study, J. Mar. Sys., 52, 191-215, 2004.

Behrenfeld, M. J., O’Malley, R. T., Siegel, D. A., McClain, C. R., Sarmiento, J. L., Feldman, G. C., Milligan, A. J., Falkowski, P. G., Letelier, R. M., and Boss, E. S.: Climatedriven trends in contemporary ocean productivity, Nature, 444, doi:10.1029/2007GL031745, 2006.

Bracher, A., Vountas, M., Dinter, T., Burrows, J. P., Röttgers, R., and Peeken, I.: Quantitative observation of cyanobacteria and diatoms from space using PhytoDOAS on SCIAMACHY data, Biogeosciences, 6, 751-764, doi:10.5194/bg-6-751-2009, 2009.

Brewin, R. J. W., Sathyendranath, S., Hirata, T., Lavender, S., Baraciela, R. M., and Hardman-Mountford, N.: A three-component model of phytoplankton size class for the Atlantic ocean, Ecol. Model., 221, 11, 1472-1483, 2010.

Brewin, R. J. W., Hardman-Mountford, N. J., Lavender, S. J., Raitsos, D. E., Hirata, T., Uitz, J., Devred, E., Bricaud, A., Ciotti, A. M., and Gentili, B: An intercomparison of bio-optical techniques for detecting dominant phytoplankton size class from satellite remote sensing, Remote Sens. Environ., 115, 325-339, 2011.

Ciotti, A. M. and Bricaud, A.: Retrievals of a size parameter for phytoplankton and spectral light absorption by coloured detrital matter from water-leaving radiances at SeaWiFS channels in a continental shelf off Brazil, Limnol. Oceanogr. Methods, 4, 237253, 2006.

Devred, E., Sathyendranath, S., Stuart, V., Maass, H., Ulloa, O., and Platt, T.: A two-component model of phytoplankton absorption in the open ocean: Theory and applications, J. Geophys. Res., 111, C03011, doi:10.1029/2005JC002880, 2006.

Fishwick, J. R., Aiken, J., Barlow, R., Sessions, H., Bernard, S., and Ras, J.: Functional relationships and bio-optical properties derived from phytoplankton pigments, optical and photosynthesis paramters; a case study of the Benguela ecosystem, J. Mar. Biol. Assoc. U.K., 86, 1267-1280, 2006.

Gall, M. P., Boyd, P. W., Hall, J., Safi, K. A., and Chang H.: Phytoplankton processes. Part 1: community structure during the Southern Ocean Iron Release Experiment (SOIREE), Deep-Sea Res. Pt. II, 48, 2551-2570, 2001.

Grob, C., Ulloa, O., Claustre, H., Huot, Y., Alarcón, G., and Marie, D.: Contribution of picoplankton to the total particulate 
organic carbon concentration in the eastern South Pacific, Biogeosciences, 4, 837-852, doi:10.5194/bg-4-837-2007, 2007.

Gregg, W. W., Ginoux, P., Schopf, P. S., and Casey, N. W.: Phytoplankton and iron: validation of a global three-dimensional ocean biogeochemical model, Deep Sea Res. Pt. II, 50, 31433169, 2003.

Gregg, W. W. and Casey, N.W.: Modeling coccolithophores in the global oceans, Deep Sea Res. Pt. II, 54, 447-477, 2007.

Hardman-Mountford, N. J., Hirata, T., Richardson, K., and Aiken, J.: An objective methodology for the classification of ecological pattern into biome and provinces for the pelagic ocean, Remote Sens. Environ., 112, 3341-3352, 2008.

Hashioka, T. and Yamanaka, Y.: Ecosystem change in western North Pacific associated with global warming using 3DNEMURO, Ecol. Model., 202, 95-104, 2007.

Hirata, T., Aiken, J., Hardman-Mountford, N., Smyth T. J., and Barlow, R.: An absorption model to determine phytoplankton size classes from satellite ocean colour, Remote Sens. Environ., 112, 3153-3159, 2008.

Isada, T., Kuwata, A., Saito, H., Ono, T., Ishi, M., YoshikawaInoue, H., and Suzuki, K.: Photosynthetic features and primary productivity of phytoplankton in the Oyashio and KuroshioOyashio trasition regions of the northwest Pacific, J. Plankton Res., 31, 1009-1025, 2009.

Kishi, M. J., Kashiwai, M., Ware, D. M., Megrey, B. A., Eslinger, D. L., Werner, F. E., Noguchi-Aita, M., Azumaya, T., Fujii, M., Hashimoto, S., Huang, D., Iizumi, H., Ishida, Y., Kang, S., Kantakov, G. A., Kim, H., Komatsu, K., Navrotsky, V. V., Smith, S. L., Tadokoro, K., Tsuda, A., Yamamura, O., Yamanaka, Y., Yokouchi, K., Yoshie, N., Zhang, J., Zuenko Y. I., and Zvalinsky, V. I.: NEMURO-a lower trophic level model for the North Pacific marine ecosystem, Ecol. Model., 202, 12-25, 2007.

Kostadinov, T. S., Siegel, D. A., and Maritorena, S.: Global variability of phytoplankton functional types from space: assessment via the particle size distribution, Biogeosciences, 7, 3239-3257, doi:10.5194/bg-7-3239-2010, 2010.

Le Quéré, C., Harrison, S. P., Prentice, I. C., Buitenhuis, E. T., Aumont, O. , Bopp, L., Claustre, H., Cotrim Da Cunha, L., Geider, R., Giraud, X., Klaas, C., Kohfeld, K. E., Legendre, L., Manizza, M., Platt, T., Rivkin, R. B., Sathyendranath, S., Uitz, J., Watson, A. J., and Wolf-Gladrow, D.: Ecosystem dynamics based on plankton functional types for global ocean biogeochemistry models, Glob. Change Biol., 11, 2016-2041, 2005.

Le Quéré, C. and Pesant, S.:Plankton functional types in a new generation of biogeochemical models, EOS, 90, 30-31, 2009.

Liu, H., Probert, I., Uitz, J., Claustre, H., Aris-Brosou, S., Frada, M., Not, F., and de Vargas, C.: Extreme diversity of noncalcifying haptophytes explains a major pigment paradox in open oceans, Proceedings of National Academy of Science of the United States of America, 106, 12803-12808, 2009.

Longhurst, A., Sathyendranath, S., Platt, T., and Caverhill, C.: An estimate of global primary production in the ocean from satellite radiometer data, J. Plankton Res., 17, 1245-1271, 1995.

McClain, C. R.: A Decade of Satellite Ocean Color Observation, Annu. Rev. Mar. Sci., 1, 19-42, 2009.

Mouw, C. B. and Yorder, J. A.: Optical determination of phytoplankton size composition from global SeaWiFS imagery, J. Geophys. Res., 115, C12018, doi:10.1029/2010JC006337, 2010. National Geophysical Data Center: Data Announcement 88-MGG-
02, Digital relief of the Surface of the Earth. NOAA, Boulder, Colorado, http://www.ngdc.noaa.gov/mgg/global/etopo5. HTML, 1988.

Obayashi, Y., Tanoue, E., Suzuki, K., Handa, N., Nojiri, Y., and Wong, C. S.: Spatial and temporal variabilities of phytoplankton community structure in the northern North Pacific as determined by phytoplankton pigments, Deep Sea Res. Pt. I, 48, 439-469, 2001.

O'Reilly, J. E., Maritorena, S., Mitchell, B. G., Siegel, D. A., Carder, K. L., Garver, S. A., Kahru, M., and McClain, C.: Ocean color chlorophyll algorithm for SeaWiFS, J. Geophys. Res., 103(C11), 24937-24953, 1998.

Polovina, J. J., Howell, E., Kobayashi, D. R., and Seki, M. P.: The transition zone chloropyll front, a dynamic global feature defining migration and forage habitat for marine resources, Progr. Oceanogr., 49, 469-483, 2001.

Polovina, J. J., Howell, E. A., and Abecassis, M.: Oceans least productive waters are expanding, Geophys. Res. Lett., 35, L03618, doi:10.1029/2007GL031745, 2008.

Petihakis, G., Triantafyllou, G., Pollani, A., Koliou, A., and Theodorou, A.: Field data analysis and application of a complex water column biogeochemical model in different areas of a semi-enclosed basin: towards the development of an ecosystem management tool, Mar. Environ. Res., 59, 493-518, 2005.

Ras, J., Claustre, H., and Uitz, J.: Spatial variability of phytoplankton pigment distributions in the Subtropical South Pacific Ocean: comparison between in situ and predicted data, Biogeosciences, 5, 353-369, doi:10.5194/bg-5-353-2008, 2008.

Raitsos, D. E., Lavender, S. J., Maravelias, C. D., Haralambous, J., Richardson, A. J., and Reid, P. C.: Identifying four phytoplankton functional types from space: An ecological approach, Limnol. Oceanogr., 53, 2, 605-613, 2008.

Sathyendranath, S., Watts, L., Devred, E., Platt, T., Caverhill, C., and Maass, H.: Discrimination of diatoms from other phytoplankton using ocean-colour data, Mar. Ecol. Prog. Ser., 272, 59-68, 2004.

Sieburth, J. M., Smetacek, V., and Lenz, J.: Pelagic ecosystem structure: heterotrophic compartments of the plankton and their relationship to plankton size fractions, Limnol. Oceanogr., 23, 1256-1263, 1978.

Sunda, W., Kieber, D. J., Kiene, R. P., and Huntsman, S.: An antioxidant function for DMSP and DMS in marine algae, Nature, 418, 317-320, 2002.

Suzuki, K., Hinuma, A., Saito, H., Kiyosawa, H., Liu, H., Saino, T., and Tsuda, A.: Responses of phytoplankton and heterotrophic bacteria in the northwest subarctic Pacific to in situ iron fertilization as estimated by HPLC pigment analysis and flow cytometry, Prog. Oceanogr., 64, 167-187, 2005.

Tarran, G. A., Heywood, J. L., and Zubkov, M. V.: Latitudal changes in the standing stocks of nano- and picoeukaryotic phytoplankton in the Atlantic Ocean, Deep Sea Res. Pt. II, 53, 15161529, 2006.

Uitz, J., Claustre, H., Morel, A., and Hooker, S. B.: Vertical distribution of phytoplankton communities in open ocean, An assessment based on surface chlorophyll, J. Geophys. Res., 111, C08005, doi:10:1029/2005JC003207, 2006

Vidussi, F., Claustre, H., Manca, B. B., Luchetta, A., and Marty, J.: Phytoplankton pigment distribution in relation to upper thermocline circulation in the eastern Mediterranean Sea during winter, 
J. Geophys. Res., 106 (C9), 19939-19956, 2001.

Werdell, P. J. and Bailey, S. W.: An improved in-situ bio-optical data set for ocean color algorithm development and satellite data product validation, Remote Sens. Environ., 98, 122-140, 2005.

Wright, S. W. and Jeffrey, S. W.: Pigment markers for phytoplankton production, Hdb. Env. Chem, 2, Part N, 71-104, 2006.

Zwirglmaier, K., Heywood, J. L., Chamberlain K., Woodward, E. M. S., Zubkov, M., and Scanlan, D. J.: Basin-scale distribution patterns of picocyanobacterial lineages in the Atlantic Ocean, Environ. Microbiol., 9, 1278-1290, 2007.
Zwirglamaier, K., Jardillier, L., Ostrowski, M., Mazard, S., Garczarek, L., Vaulot, D., Not, F., Massana, R., Ulloa, O., and Scanlan, D. J.: Global phylogeography of marine Synechococcus and Prochlorococcus reveals a distinct partioning of lineages among oceanic bioms, Environ. Microbiol., 10, 147-161, 2008.

Zubkov, M. V., Sleigh, M. A., Tarran, G. A., Burkill, P. H., and Leakey, R. J. G.: Picoplanktonic community structure on an Atlantic transect from 50N to 50S, Deep Sea Res. Pt. I, 45, 13391335, 1998. 